Relmecs, diciembre 2017, vol. 7, no. 2, e025, ISSN 1853-7863

Universidad Nacional de La Plata. Facultad de Humanidades y Ciencias de la Educación. Centro Interdisciplinario de Metodología de las Ciencias Sociales.

Red Latinoamericana de Metodología de las Ciencias Sociales

\title{
Problematización de la complejidad de los sistemas de pensamiento: un modelo epistemológico para la investigación empírica de los paradigmas
}

\section{Problematization of the complexity of thought systems: an epistemological model for empirical research on paradigms}

\section{Leonardo G. Rodríguez Zoya *}

* Consejo Nacional de Investigaciones Científicas y Técnicas, Argentina | leonardo.rzoya@gmail.com

\section{PALABRAS CLAVE}

Pensamiento complejo

Problemas complejos

Paradigma

Sistemas de creencias científicas

\section{KEYWORDS}

Complex thought

Complex problems

Paradigm

System of scientific beliefs

\section{RESUMEN}

Este trabajo recupera uno de los aspectos más relevantes de la obra de Edgar Morin: la problematización del paradigma y la organización de los sistemas de pensamiento. Asimismo, elabora una estrategia para superar una de las más fuertes limitaciones de su obra: la carencia de una metodología empírica para desarrollar el pensamiento complejo en el plano de la investigación científica. La estrategia argumental está organizada en tres momentos. Primero se problematiza la complejidad de los sistemas de pensamiento. Segundo se elabora el concepto de problemas complejos. Tercero se propone un modelo epistemológico para la investigación empírica de los paradigmas.

\section{ABSTRACT}

This paper revisits one of the most relevant aspects of Edgar Morin's work: the problematization of paradigms and organization of thought systems. Likewise, the paper elaborates a strategy for overcoming one of the stronger limitations of its work: the lacks of an empirical methodology to develop the complex thought in the domain of scientific research. This paper is organized as follows. First, we problematize the complexity of thought systems. Second, we propose and develop the category of complex problems. Finally, we outline an epistemological model for empirical research on paradigms. 


\section{Introducción}

La controversia entre el pensamiento complejo desarrollado por Edgar Morin (1990) y las ciencias de la complejidad (Waldrop, 1992) constituye un campo de disputa epistemológico y metodológico acerca de cómo pensar e investigar la complejidad organizacional del mundo físico, biológico y antroposocial. No se trata, ciertamente, de una simple disputa académica, sino de una controversia con implicancias filosóficas, educativas e incluso políticas. Cabe destacar que ambos enfoques se han desarrollado de modo independiente y con escasos puntos de contacto entre sí, desde fines de la década de 1970, por lo que cabe referir una ignorancia mutua entre el pensamiento complejo y las ciencias de la complejidad (Roggero, 2008) . Por esta razón, no resulta apropiado hablar de una disputa controversial sino hasta comienzos del siglo XXI cuando se inician los primeros diálogos críticos entre ambas tradiciones de pensamiento.

En tal sentido, el filósofo francés planteó por primera vez una referencia explícita a las ciencias de la complejidad en el año 2005 -casi treinta años después de la aparición del primer tomo de El Método (Morin, 1977)-, en ocasión del coloquio de Cerisy. En su intervención, el autor de El Método propuso la distinción entre la complejidad generalizada y la complejidad restringida. Mientras que la primera corresponde a su concepción del pensamiento complejo, la segunda refiere a las ciencias de la complejidad (Morin, 2007). Si bien Edgar Morin abogó por la convergencia y articulación de ambas concepciones de complejidad, lo cierto es que el autor francés no acometió tal tarea en el desarrollo de su obra. Asimismo, la labor intelectual de los autores próximos al pensamiento complejo se ha orientado más hacia la exégesis y sistematización del corpus moriniano que hacia la revisión crítica del mismo (Ciurana, 2007; Solana Ruiz, 2001) . De este modo, el pensamiento complejo no ha abierto su campo de reflexión a las problemáticas metodológicas y técnicas a las cuales se confrontan las ciencias de la complejidad.

Por otro lado, desde América Latina, algunos autores próximos a las ciencias de la complejidad dirigieron una crítica a la obra de Edgar Morin a través del señalamiento de sus limitaciones y destacando el carácter antagónico y, posiblemente, inconmensurable entre ambos enfoques (Maldonado, 2007; Reynoso, 2009). Esto condujo a la cristalización de una serie de dicotomías entre teorías discursivas de la complejidad y algoritmos complejos (Reynoso, 2006); modelos formales construidos con lenguaje matemático o computacional y metáforas elaboradas en lenguaje natural (Reynoso, 2009); la complejidad como método y la complejidad como ciencia (Maldonado, 1999 y 2007). Por esta vía se bloqueó la posibilidad de un diálogo mutuamente constructivo entre ambas tradiciones y se profundizó la escisión entre pensamiento complejo y ciencias de la complejidad.

En el marco de este espacio controversial, el presente trabajo tiene un doble propósito. Por un lado, una de las problematizaciones más relevantes de la obra de Edgar Morin: el problema del paradigma y la organización de los sistemas de pensamiento. Por el otro lado, elaborar una estrategia posible para superar una de sus más fuertes limitaciones: la carencia de una metodología empírica que permita desarrollar el pensamiento complejo en el plano de la investigación científica.

En estas coordenadas, el objetivo específico de este artículo es explorar la pregunta acerca de cómo y por qué modelizar la complejidad de los sistemas de pensamiento. Para este fin se elabora una reflexión teórica y se propone un modelo epistemológico del pensamiento complejo para la investigación empírica de los paradigmas, esto es, los principios organizadores de un sistema de pensamiento. Este modelo es un dispositivo teórico y metodológico para examinar interrogantes del tipo: ¿cómo piensan los científicos la dimensión epistémica, social, ética y política de sus propias prácticas científicas?, ¿cómo un paradigma, o modo de pensamiento, determina un modo de problematización, esto es, el horizonte de las preguntas posibles, las ideas concebibles, los problemas aceptables y los conceptos imaginables?, ¿cómo una ciencia o disciplina científica puede ser capaz de observar, problematizar y criticar su propio paradigma o modo de pensamiento?

La labor desarrollada en este artículo forma parte de una línea de trabajo cuya meta, en el mediano plazo, es 
desarrollar estratégicamente las potencialidades del enfoque del pensamiento complejo y de las ciencias de la complejidad como un programa de investigación interdisciplinario de problemas complejos con alcances sociales y políticos.

El horizonte programático de esta línea de trabajo se orienta por un supuesto general que puede expresarse mediante el siguiente argumento. Las sociedades contemporáneas se enfrentan a múltiples problemas complejos de orden ecológico (degradación de la biósfera y cambio climático), económico (regulación de los mercados financieros), social (pobreza, hambre, desigualdad) y político (violencia, terrorismo, violación de los derechos humanos), entre otros. Transformar los problemas complejos en situaciones más deseables plantea a la humanidad tres grandes desafíos. Primero, construir un conocimiento más pertinente de los problemas complejos (desafío epistémico). Segundo, desarrollar acciones estratégicas, de carácter colectivo y democrático, para transformar el estado actual de un problema complejo en un futuro mejor (desafío ético-político). Tercero, pensar cómo pensamos la complejidad de los problemas fundamentales de la humanidad, del conocimiento que construimos y de las decisiones y estrategias de acción e intervención sobre la realidad (desafío meta-cognitivo y reflexivo).

Este último desafío constituye un problema invisible y difícil de ser pensado, justamente, porque implica desarrollar un proceso de objetivación y autoobservación sobre nuestro propio sistema de pensamiento o paradigma. Nuestro modo de pensamiento juega un rol crucial en las interrogaciones, conceptualizaciones, estrategias y decisiones que elaboramos para enfrentar problemas complejos. Es por esta razón que el problema del pensamiento es uno de los mayores desafíos políticos, educativos y científicos que enfrenta la humanidad en el siglo XXI. La posibilidad de imaginar y construir un sistema-mundo alternativo, esto es, un modo de vida sustentable en términos éticos, ecológicos, sociales, económicos y políticos está íntimamente ligada a nuestra capacidad de aprender a pensar de otro modo o, lo que es lo mismo, transformar nuestro sistema de pensamiento o paradigma.

¿Puede la ciencia ayudarnos a pensar la complejidad de nuestros problemas más graves? Es posible. Para ello la ciencia tiene que ser capaz de pensarse a sí misma, es decir, problematizar su propia estructura de pensamiento. ¿Cómo puede una ciencia investigar los paradigmas que organizan sus propias prácticas de construcción de conocimiento? Para abordar este problema, este trabajo se propone bosquejar una estrategia para modelizar la complejidad de los sistemas de pensamiento. Construir un modelo de los paradigmas o principios organizadores del sistema de pensamiento de una ciencia (o cualquier otro grupo u organización humana) constituye un metapunto de vista a través del cual los científicos pueden autoobservar, problematizar y criticar sus estrategias de construcción de conocimiento. La elaboración de un meta-punto de vista constituye una estrategia metacognitiva que posibilita la inclusión reflexiva del sujeto en el conocimiento que produce y, por esta vía, la construcción de un conocimiento del conocimiento y de una ciencia con conciencia de la complejidad de su propia práctica y su propio modo de pensar (Morin, 1984).

La estrategia argumentativa está organizada en tres momentos. En primer lugar, se problematiza la complejidad del proceso de pensamiento como objeto de estudio y como método de conocimiento. En segundo lugar, se propone y elabora la categoría de problemas complejos. Se pone en evidencia la necesidad de articular métodos de objetivación y métodos reflexivos en la investigación empírica de tales problemas. Finalmente, se presenta un modelo epistemológico para la investigación empírica de los sistemas de pensamiento. Este modelo es ilustrado empíricamente a través de una aplicación al dominio de las ciencias de la complejidad y la simulación social.

\section{El pensamiento como sistema complejo}

En su clásico trabajo La arquitectura de la complejidad, Herbert Simon (1973) señala que un sistema puede ser descripto desde dos puntos de vista: como una descripción de estados y como una descripción de procesos. En el primer caso, se trata de un análisis estructural orientado a comprender la organización de un sistema en un momento particular de su historia. En el segundo caso, se trata de un análisis de la dinámica del sistema, es decir, su evolución a lo largo del tiempo. 
Los sistemas complejos (físicos, biológicos y antroposociales) son sistemas históricos, esto quiere decir que la organización de un sistema es el resultado de un proceso evolutivo. Por esta razón, Jean Piaget (1979, p. 117) argumenta que existe "una necesidad fundamental de una dialéctica de la génesis y de la estructura", de modo tal que "no hay estructura sin historia, ni historia sin estructura” (García, 2006, p. 81) . Más aún, puede afirmarse que “una estructura es historia organizada” (Rodríguez Zoya, 2013, p. 84) . Metodológicamente, la dinámica evolutiva de un sistema comprende: (i) fases estructurantes que corresponden a los procesos de génesis y construcción de nuevas estructuras; (ii) fases estructuradas que comprenden los mecanismos que permiten conservar la organización de un sistema; y (iii) fases de desestructuración y reestructuración que aluden a la ruptura y cambio de la estructura de un sistema.

La pregunta central al estudiar el pensamiento como sistema complejo puede resumirse en el siguiente interrogante: ¿cómo se construye, cómo se organiza y cómo cambia el pensamiento a lo largo del tiempo? El problema relativo a la organización y cambio de los sistemas de pensamiento ha sido abordado desde distintas perspectivas y con distintos conceptos: psicogénesis y sociogénesis (Piaget y García, 2008), paradigma (Morin, 1998) , arqueología y genealogía (Foucault, 1998) , estructura o marco de pensamiento (Koyré, 1999) , representaciones sociales (Moscovici, 1979) , mindscape (Maruyama, 1980) , modo de pensamiento (Whitehead, 1944), entre otros.

En el marco de este trabajo no podemos discutir estas perspectivas ni abordar con profundidad dicho interrogante. No obstante, interesa sugerir que el problema de la constitución, organización y cambio del pensamiento constituye, posiblemente, la pregunta conductora central de un programa de investigación interdisciplinario sobre la complejidad de los sistemas de pensamiento. A continuación, se ofrecen algunas líneas de reflexión para pensar la complejidad del pensamiento. Primero, se explora el bucle recursivo entre la organización del pensamiento y la organización de la realidad (apartado 2.1); segundo, se caracteriza al pensamiento como proceso de construcción de modelos (apartado 2.2); tercero, se describe al pensamiento como proceso de problematización (apartado 2.3); y finalmente, se aborda la relación entre la complejidad del pensamiento como objeto de estudio y el pensamiento complejo como método (apartado 2.4).

\subsection{El bucle recursivo entre el pensamiento y la realidad}

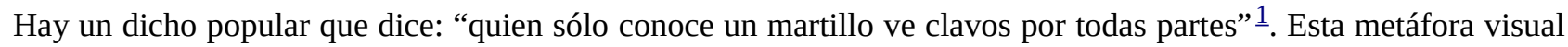
tiene valor heurístico para problematizar la relación entre el pensamiento y la realidad. Nuestros instrumentos de conocimiento (por ejemplo un estilo de pensamiento, una teoría, una conceptualización, un modelo científico, un método de investigación) condicionan nuestro modo de percibir y organizar la realidad.

Planteemos un experimento mental. Alguien muestra una fotografía de una selva. Llamemos a este objeto el sistema observado. Consideremos una multiplicidad de observadores. Ahora, alguien pregunta ¿qué ven? Un individuo cualquiera dice: "una selva, árboles, plantas”. Un estudiante responde: “clorofila y fotosíntesis". Un poeta enuncia: "el color de la vida antes del hombre”. Un ingeniero agrónomo afirma: "hay allí al menos cinco especies de plantas”. Un físico-químico plantea: "un proceso termodinámico de disipación de energía”. Un ecologista declara: "un ecosistema, un fragmento de la biósfera y de GAIA”.

Todos miran el mismo objeto pero no todos observan lo mismo (Hanson, 1958). Distintos sistemas observadores tienen diferentes puntos de vista sobre un mismo recorte de la realidad empírica. El pensamiento es un punto de vista que estructura un modo de percibir y organizar la experiencia de la realidad. Pero, al mismo tiempo, los fenómenos del mundo de la experiencia condicionan la estructuración del pensamiento. El pensamiento y la realidad no son dos entidades discretas y separadas ni es posible establecer entre ellos una prioridad ontológica. Tanto el constructivismo ontológico (Latour, 1999; Woolgar, 1991) como el realismo ontológico (Bunge, 2009; Putnam, 1994) constituyen dos formas de simplificación. Más bien, puede sostenerse que la organización del pensamiento y la organización de la realidad son procesos correlativos y mutuamente constitutivos, tal como ha sido demostrado empíricamente por la psicología social (Duveen y Lloyd, 1990; Moscovici, 1979), la 
epistemología genética (García, 2000; Piaget y García, 2008) y la biología del conocimiento (Maturana y Varela, 1972 y 2003), entre otras disciplinas. La complejidad reside en el carácter recursivo del proceso a través del cual el pensamiento constituye la realidad al tiempo que es constituido por ésta. Lo que llamamos realidad es una estructuración histórica de ese proceso recursivo. La reorganización de un sistema de pensamiento implica, de modo concomitante, transformaciones profundas en la organización de la realidad. Por ejemplo, la cosmología aristotélica es radicalmente distinta a la cosmología moderna que emerge del pensamiento de Tycho Brahe, Galileo y Kepler, entre otros, y cuya síntesis efectúa Newton. La reorganización del sistema de pensamiento aristotélico-tomista en un pensamiento moderno implicó lo que Alexandre Koyré llamo la "destrucción del cosmos" (finito, cerrado y jerárquico de los antiguos y la construcción de un nuevo cosmos infinito) y la "geometrización del espacio" (la sustitución del espacio aristotélico por el de la geometría euclidiana). La constitución del sistema de pensamiento moderno implicó, en su sentido más profundo:

que el hombre perdiese su lugar en el mundo o, quizás más exactamente, que perdiese el propio mundo en el que vivía y sobre el que pensaba, viéndose obligado a transformar y sustituir no sólo sus conceptos y atributos fundamentales, sino incluso el propio marco de pensamiento (Koyré, 1999, p. 6. Énfasis agregado).

\subsection{El pensamiento como proceso de modelización}

El filósofo y poeta Paul Valéry dice: "No razonamos más que a través de modelos”. El pensamiento puede ser concebido como un proceso a través del cual construimos modelos con los cuales observamos, cuestionamos e interpretamos el mundo, nuestra relación con los otros y con nosotros mismos. El concepto de modelo mental es una hipótesis plausible de las ciencias cognitivas que sugiere que los individuos construyen representaciones cognitivas de las situaciones prácticas en las que actúan (Johnson-Laird, 1983 y 1987) . El lógico Jean-Blaise Grize plantea que "toda acción, todo comportamiento y, en particular, todo discurso reposa sobre el modelo mental de una realidad específica” (Grize, 1993, p. 3) . De manera que un modelo mental representa el punto de vista de un observador $\mathrm{X}$ sobre una experiencia $\mathrm{Z}$.

A partir de la observación de Valéry, el pensador sistémico Jean-Louis Le Moigne (1990, p. 15) se interroga acerca de "cómo construimos los modelos a través de los cuales razonamos". Puede afirmarse que los modelos son estructuras históricas, sociales y cognitivas elaboradas a través del lenguaje y la comunicación social. Los modelos son históricos porque no son inmutables, sino que cambian con el tiempo. Además, son sociales por ser irreductibles a la mente individual y porque suponen una materia social proveniente del lenguaje y la cultura. Finalmente, los modelos son construcciones cognitivas porque constituyen una forma de conocimiento.

Los modelos mentales son construcciones cognitivas individuales puesto que son elaboraciones personales y no compartidas por otras personas (van Dijk, 1999). Sin embargo, esto no implica afirmar que los modelos mentales sean producciones cognitivas asociales. Bien por el contrario, la elaboración de un modelo mental entraña necesariamente el lenguaje interno como material simbólico inherente al ejercicio del pensamiento (Voloshinov, 1976, pp. 25-26) . La psicología histórico-cultural sugiere que el pensamiento es lenguaje interiorizado (Vygotski, 1995) . Esta perspectiva permite superar el principio de tercio excluso de la lógica clásica que conduce a establecer una disyunción entre lo mental y lo social, lo cognitivo y lo cultural, lo individual y lo colectivo. En este sentido, la sociedad y la cultura constituyen un tercio incluso constitutivo del pensamiento individual.

Los modelos mentales, aunque construidos con el lenguaje interior, son estructuras no comunicativas en el sentido que no presuponen el discurso y la interacción socioverbal entre sujetos. A este respecto, Grize (2012) propone el concepto de esquematización para señalar la formulación discursiva de un modelo mental. Es justamente la dimensión comunicativa del lenguaje la que permite comprender la construcción de representaciones sociales, es decir modelos mentales socialmente producidos y compartidos a través del discurso, la comunicación y las prácticas sociales (Moscovici, 1979; van Dijk, 1999) .

Dicho esto, puede afirmarse que un modelo es una estructura simbólica construida con un lenguaje. Sin lenguaje 
no hay modelo. La idea de los modelos como construcciones lingüísticas es útil para pensar y distinguir entre modelos construidos en lenguaje natural y en lenguaje artificial. Las representaciones sociales son modelos basados en lenguaje natural que emergen de las interacciones sociales, cognitivas y comunicativas del mundo de la vida cotidiana. Son también modelos implícitos puesto que no son construidos de modo intencional y deliberado por los actores sociales.

Por otro lado, la modelización como práctica científica es el trabajo de construcción de modelos explícitos, es decir, una actividad deliberada orientada a concebir, diseñar y construir modelos. Marvin Minksy (1965) propuso una de las conceptualizaciones con mayor valor heurístico: "Para un observador $\mathrm{B}$, un objeto $\mathrm{A}^{*}$ es un modelo de un objeto A en la medida que B puede usar A* para responder preguntas que le interesen sobre A”. Esta definición permite distinguir al sujeto modelizador (B) del objeto de la modelización (A), y concebir al modelo como un instrumento de conocimiento de éste último $\left(\mathrm{A}^{*}\right)$. Además, permite pensar que todo modelo se construye en función de una pregunta, y por ende, implica la concepción de un problema. Esto permite observar la naturaleza práctica de los modelos en la medida en que todo modelo es construido por alguien (sujeto de la modelización), sobre algo (objeto de la modelización) y para algo (fines de la modelización), es decir por qué, para qué y para quién se construye un modelo. Esta última cuestión permite señalar que todo modelo está mediado por intereses que guían su construcción. Por esta razón, los modelos no son axiológicamente neutrales.

Los modelos científicos pueden estar formulados tanto en lenguaje natural como formal. En el primer caso, puede hablarse de modelos discursivos construidos con el lenguaje teórico y conceptual de una ciencia determinada.

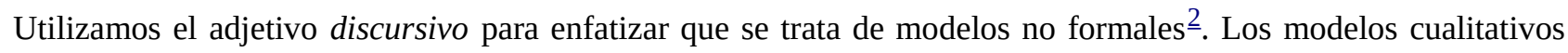
producidos por las ciencias sociales y las humanidades son un ejemplo de modelos discursivos. En el caso de los modelos formales se trata de modelos construidos en base a un lenguaje artificial, por ejemplo los modelos matemáticos (modelos basados en ecuaciones), los modelos estadísticos (basados en relaciones entre variables), y los modelos de simulación computacional (modelos escritos en un lenguaje de programación). Todo modelo formal es siempre una abstracción y simplificación de un modelo conceptual y de un modelo mental sobre el que descansa.

Para concluir, el pensamiento social y el pensamiento científico son procesos de construcción de modelos que se diferencian por el lenguaje que emplean, así como por sus finalidades y niveles de formalización.

\subsection{El pensamiento como proceso de problematización}

Un problema no es un dato de la realidad empírica. Esto quiere decir que un problema no está dado en la experiencia inmediata de modo positivo e independiente de un sujeto de conocimiento (García, 2000 y 2006) . Por el contrario, todo problema es el resultado de un proceso de problematización y, por lo tanto, una construcción emergente de una práctica social y cognitiva. Según Michel Foucault, problematizar "no quiere decir representación de un objeto preexistente, así como tampoco creación mediante el discurso de un objeto que no existe” (Foucault, 1999a, p. 1007) . El punto crucial para Foucault consiste en que laproblematización involucra un trabajo del pensamiento a través del cual éste elabora las condiciones acerca de "cómo y por qué ciertas cosas (una conducta, un fenómeno, un proceso) se convierten en un problema” (Foucault, 1988, p. 17. Énfasis en el original) .

Desde esta perspectiva, el pensamiento puede ser caracterizado como una práctica o trabajo a través del cual los seres humanos construimos fragmentos de nuestra experiencia como problemas (Foucault, 1999b) . Pensar es ejercitar el arte de la problematización, es decir, el arte de la concepción de nuevas preguntas y problemas (Morin, 1986) . El concepto de sistema de pensamiento alude al proceso mental y social, cultural y cognitivo a través del cual los individuos, los grupos y las sociedades humanas problematizan una experiencia. Un problema, cualquiera sea su tipo (social, político, económico o científico), es una experiencia constituida como objeto para el pensamiento a través de un proceso de problematización. De modo tal que diferentes sistemas de pensamientos conducen a formas distintas de problematización. 
Si el razonamiento precedente es plausible, entonces, puede afirmarse que nuestro sistema de pensamiento condiciona tanto el tipo de problematización que se construye como las soluciones que se elaboran. Así, una problematización delimita no sólo el dominio y alcance de lo que se define como problema, sino que condiciona, además, el campo de respuestas posibles. Por lo tanto, la transformación de un problema está ligada no sólo a la búsqueda de nuevas soluciones, sino fundamentalmente, al análisis crítico de lo que Edgar Morin (1998) denomina paradigmas, esto es, el examen de los principios organizadores de un sistema de pensamiento en el que se sustenta lo que se experimenta y conceptualiza como problema.

Ilustremos esta idea con un breve ejemplo de la historia de la ciencia. Toda la física desde Aristóteles hasta Galileo se hizo una misma pregunta: ¿qué es el movimiento? Para Aristóteles el estado natural de los cuerpos es el reposo, de modo tal que en ausencia de una fuerza el movimiento desaparece. El principio de inercia, formulado por Galileo y sintetizado en la primera ley de movimiento de Newton $\underline{3}$, fue imposible de imaginar y concebir por el sistema de pensamiento occidental durante más de dos mil años. Más aún, antes de Galileo la idea de movimiento permanente no ocasionado por la acción constante de una fuerza fue rechazada como absurda. (Piaget y García, 2008, p. 232) .

Un texto chino del siglo quinto a. C. afirma "la cesación del movimiento se debe a una fuerza opuesta. Si no hay fuerza opuesta, el movimiento nunca se detendrá (...) Esto es tan cierto como que una vaca no es un caballo" (Piaget y García, 2008, p. 232) . Más de dos mil años antes de Galileo y del principio de inercia, la civilización china había imaginado una concepción de movimiento similar a la de los modernos y sin embargo, no desarrollaron una mecánica ni una física como la de Galileo y Newton. ¿Cómo es posible? Según el análisis sociogenético realizado por Rolando García (2000) , en el sistema de pensamiento chino, el devenir y el cambio es el estado natural del mundo y, por lo tanto, no requiere ser explicado; mientras que en el sistema de pensamiento aristotélico-tomista, el mundo es estático y, en consecuencia, el principio de inercia no resulta concebible. Ambos sistemas de pensamiento bloquean por vías diferentes un modo de objetivación -que sí desarrollaron los modernos- en el cual el movimiento inercial se constituyó en objeto de un nuevo saber: la física clásica.

La revolución científica sintetizada en los Principia de Newton consistió en la invención de una nueva pregunta ¿Cómo se produce el movimiento? La respuesta ya no se plantea en términos de sustancias y finalidades, sino de la relación entre la acción de fuerzas que afectan a los cuerpos independientemente del tiempo.

La reorganización de un sistema de pensamiento no procede por el hallazgo de nuevas respuestas a las preguntas establecidas, ni por una ampliación acumulativa de conocimientos, sino por la invención de "nuevas preguntas que permitieron formular los problemas de manera distinta” (Piaget y García, 2008, p. 228). Ahora bien, cambiar de pregunta conductora es lo más difícil por cuanto implica "cambiar las bases del punto de partida de un razonamiento o una teoría” (Morin, 1991, p. 238) , esto es, transformar el paradigma o principio organizador del sistema de pensamiento. Un paradigma condiciona una forma de problematización, esto es, el campo de las preguntas pensables, de los problemas considerados aceptables y de las ideas concebibles e imaginables. Es por esta razón que la investigación teórica y empírica de problemas sociales concretos es inseparable de la problematización de los paradigmas que estructuran nuestro sistema de pensamiento y la forma en que problematizamos la experiencia.

\subsection{Complejidad del pensamiento y pensamiento complejo}

Uno de los rasgos distintos de la obra de Edgar Morin $(1986,1990)$ consiste en problematizar el pensamiento como un fenómeno complejo. Más aún, el trabajo antropológico de Morin (1973 y 2001) permite destacar que el pensamiento es un rasgo distintivo de la complejidad humana ${ }^{4}$. En efecto, todas las expresiones de la cultura humana están mediadas por el pensamiento: el arte, la poesía, la ciencia, la filosofía, la política, la economía, la técnica. El pensamiento es un fenómeno que emerge de la articulación de la complejidad biológica y la complejidad sociocultural siendo irreductible a cada una de estas instancias. Desde un punto de vista evolutivo, puede señalarse que la hominización comprende un proceso de cerebralización, es decir, de aumento y 
complejización del aparato neurocerebral. La creciente complejidad sociocultural de las sociedades humanas está posibilitada por, pero no se reduce a, la complejidad biológica del cerebro (Morin, 2001) . La emergencia de la mente, la consciencia y la inteligencia es inconcebible sin el desarrollo del lenguaje de doble articulación, el cual es a su vez inconcebible sin el incremento de la complejidad cerebral (Morin, 1986) . El pensamiento, el cerebro, el lenguaje y la cultura están unidos en un proceso recursivo (Morin, 1973 y 2001) .

A partir del trabajo de Morin, es posible distinguir entre el pensamiento como objeto de conocimiento y como método de conocimiento. El primer caso supone un proceso de objetivación del pensamiento a partir del cual éste puede ser concebido como objeto de indagación, de reflexión, de experimentación. En definitiva, la construcción del pensamiento como objeto de estudio permite investigar el pensamiento a nivel teórico o empírico, científico o filosófico con el fin de producir conocimiento sobre dicho fenómeno. La complejidad del pensamiento como objeto de conocimiento reside, fundamentalmente, en que los procesos que lo constituyen pertenecen al dominio de distintas disciplinas. El pensamiento es al mismo tiempo un fenómeno neuronal, biológico, físico-químico, lingüístico, psicológico, social, cultural e histórico. Cada disciplina es una instancia necesaria pero en sí misma insuficiente para elucidar la complejidad del pensamiento. Es por esta razón que se vuelve cada vez más necesario concebir un programa de investigación interdisciplinario sobre los sistemas de pensamiento como sistemas complejos.

Por otro lado, la idea de método de pensamiento puede caracterizarse como un "arte dialógico de la concepción” (Morin, 1986, p. 205) . Examinemos esta aserción a través de tres interrogantes ¿por qué un arte?, ¿por qué un arte dialógico? y ¿por qué un arte de la concepción? En primer lugar, la idea de arte remite tanto a una praxis (acción) como a una poiesis (producción). En relación con la idea de praxis, la epistemología genética ha mostrado empíricamente que el pensamiento comienza con la acción del sujeto sobre el objeto y se desarrolla, primero, a través de la coordinación de esquemas de acción y luego, de las conceptualizaciones (García, 2000) . Por esta razón, Piaget (1973) afirma que el pensamiento es acción interiorizada. Además, la noción de arte enlaza la creatividad del artista en la concepción de nuevas ideas con la habilidad del artesano en la producción de nuevos objetos. La creatividad y la habilidad del pensar son aprendizajes mediados por el hábito, la experiencia y la práctica en un contexto social y cultural específico. De este modo, un método de pensamiento es una forma de practicar el pensamiento racional que incluye la creatividad, la praxis, el aprendizaje y el arte.

En segundo lugar, ¿por qué un arte dialógico? El concepto de dialógica elaborado por Morin remite a la unión complementaria y antagonista de dos lógicas o principios contrapuestos (Morin, 1986) . La praxis de pensamiento comporta la dialógica entre una pluralidad de operaciones cognitivas, como por ejemplo, analizar-sintetizar; distinguir-relacionar; inducir-deducir; unir lo separado-separar lo que está unido, entre otras (Morin, 1986, p. 199) . La dialógica también se distingue de la monológica, es decir, una lógica unidimensional que no puede concebir la complementariedad de ideas contrarias.

Adicionalmente, la noción de dialógica remite al diálogo y, en este sentido, puede asociarse con la etimología de la palabra dialéctica que proviene del verbo griego dialégomai: 'arte del diálogo y contraposición argumental'. El diálogo es un proceso discursivo que presupone un vínculo con otro. Aunque el pensamiento supone siempre una dimensión cognitiva individual, el desarrollo del pensamiento implica la mediación reflexiva del otro, como dice Ricoeur (1996) “el otro es constitutivo del sí mismo”. Así, en la perspectiva de Morin, la práctica de un método de pensamiento requiere aprender a pensar por uno mismo y aprender a pensar con otro.

Finalmente, ¿por qué un arte de la concepción? El concepto de concepción alude a la creación de una novedad cualitativa. Puede decirse que pensar es concebir nuevas ideas, nuevos conceptos, nuevas preguntas, nuevos objetos, nuevas obras. La noción de concepción enlaza la idea de creatividad, imaginación e innovación: pensar es imaginar creativamente la novedad, es decir, concebir lo no advenido a la existencia. Por esta razón, puede afirmarse que nuestra práctica de pensamiento es nuestro recurso metodológico más preciado. Lo propio del pensamiento no es contemplar ni reflejar un mundo exterior, sino transformar (Piaget, 1973) . El pensamiento es una praxis constructiva, de carácter social y cognitivo, que permite crear, organizar y transformar relaciones entre objetos, acciones y conceptualizaciones. Un método de pensamiento es una práctica del pensar que permite 
construir nuevo conocimiento.

Una práctica o método de pensamiento supone dos niveles de análisis: el pensamiento de primer orden y el pensamiento de segundo orden. Por un lado, el pensamiento de primer orden es un pensamiento centrado en el objeto. En este sentido, la práctica de pensamiento consiste en un proceso de objetivación a través del cual una experiencia se constituye como objeto para el pensamiento. Toda ciencia, todo arte, toda acción y decisión supone un pensamiento de primer orden a través del cual se problematiza, organiza e interpreta una experiencia.

Por otro lado, el pensamiento de segundo orden comprende el desarrollo del pensamiento del pensamiento, esto es, un movimiento reflexivo por el cual el pensamiento se constituye en objeto para sí mismo. Este nivel de análisis ha sido denominado de diversos modos: reflexividad, metacognición, conocimiento de segundo orden, epistemología compleja o conocimiento del conocimiento.

La formación de un pensamiento complejo, sugerida por Edgar Morin (1977 y 1990), constituye un tipo de método o praxis del pensamiento racional. El pensamiento complejo como método supone la articulación creativa y rigurosa de métodos de objetivación (pensamiento de primer orden) y métodos reflexivos (pensamiento de segundo orden). Una práctica compleja del pensamiento implica la construcción de un pensamiento capaz de pensarse a sí mismo con el fin de problematizarse, conocerse y autocriticarse. En este sentido, el desarrollo del pensamiento complejo es una estrategia para la construcción de un conocimiento reflexivo. La meta de un pensamiento del pensamiento no es otra que elucidar, problematizar y criticar la organización de los sistemas de pensamiento o paradigmas, es decir, las estructuras mentales con las cuales percibimos, interrogamos, comprendemos y organizamos el mundo de la experiencia.

\section{Objetividad y reflexividad en el estudio interdisciplinario de problemas complejos}

En las últimas tres décadas se ha desarrollado de modo vigoroso la producción teórica, la investigación empírica y la reflexión filosófica sobre sistemas complejos, ciencias de la complejidad y pensamiento complejo, entre otras numerosas expresiones alusivas al vasto y heterogéneo campo de 'la complejidad' (Gell-Mann, 1995; Morin, 1977; Prigogine y Nicolis, 1997). Sin embargo, se destaca una notable carencia: pocos o nulos esfuerzos han sido dirigidos a pensar y desarrollar la categoría de problemas complejos de modo epistemológicamente riguroso y metodológicamente operativo para conducir a investigaciones colectivas de problemas concretos de las sociedades contemporáneas.

El objetivo de esta sección es proponer y bosquejar la categoría de problemas complejos. Asimismo, se conjetura que la investigación empírica de problemas complejos requiere articular métodos de objetivación (como las estrategias de modelado y simulación de sistemas complejos) y métodos reflexivos (como la estrategia de conocimiento del pensamiento complejo). Ambos métodos permiten destacar el entrelazamiento de dos dimensiones de la complejidad: la complejidad objetivada y la complejidad reflexiva. Primero, la objetivación de la complejidad es indispensable para explicar la organización, el funcionamiento y la dinámica de un problema complejo, así como para imaginar y visibilizar alternativas estratégicas para su transformación. Segundo, la complejidad reflexiva es necesaria para construir un meta-punto de vista que permita objetivar el paradigma que organiza nuestro sistema de pensamiento y, por consiguiente, pensar cómo pensamos la complejidad de un problema y los modos de objetivación de una experiencia. En suma, puede decirse que la concepción de un problema complejo implica un bucle recursivo entre los procesos de objetivación y los procesos reflexivos.

¿Por qué un problema puede ser denominado complejo? ¿Qué es lo que hace complejo a un problema? Existe un amplio debate acerca de la definición del término complejidad (Edmonds, 1999). Sin embargo, la definición de un término no es siempre un buen punto de partida teórico y epistemológico para una investigación. De hecho, en toda ciencia hay conceptos que no se definen, por ejemplo, la matemática define número natural, número primo, etcétera, pero no define número (García, 2000) . De manera que en lugar de elaborar una definición de complejidad, se propone conceptualizar cuatro dimensiones relevantes para caracterizar la noción de problemas 
complejos: la dimensión ético-política (apartado 3.1), la dimensión práctica (apartado 3.2), la dimensión epistémica (apartado 3.3) y la dimensión metodológica (apartado 3.4), lo que permite elaborar una síntesis provisional del concepto de problema complejo (apartado 3.5). No se afirma que ésta sea la única conceptualización posible. Bien por el contrario, lo que se sostiene es que se trata de una conceptualización relevante para pensar la complejidad de los problemas fundamentales de las sociedades contemporáneas.

\subsection{La dimensión ético-política de los problemas complejos}

Como se dijo previamente un problema no está dado en la realidad inmediata, sino que es una construcción emergente de un proceso de problematización. Este proceso implica que un aspecto de la experiencia (denominado el sistema observado) es percibido, evaluado y concebido como problemático por alguien -un individuo, un grupo, una comunidad, una sociedad- (denominado el sistema observador), en virtud de ciertos valores, creencias y conocimientos. Por consiguiente, la objetivación de una experiencia como problema implica juicios de valor. Un proceso de problematización es un proceso valorativo a través del cual un sistema observador juzga y evalúa una experiencia como problemática. A través de ese proceso, un sistema observador identifica, selecciona y abstrae aspectos, relaciones, datos e informaciones de la realidad empírica para construir una experiencia como problema. La etiqueta problema complejo asociada a un fenómeno empírico alude a la construcción de un sistema observado por parte de un sistema observador.

¿Por qué una experiencia se vuelve problemática? Por múltiples razones diferentes. En efecto, factores de muy diverso talante se entrelazan en un proceso de problematización: factores políticos, económicos, sociales, culturales, conocimientos científicos, opiniones, juicios éticos, valores, opiniones, creencias.

El punto crucial es que los problemas de la vida social, política, económica y ecológica son complejos porque implican lo que Putnam (2004) ha denominado imbricación o entrelazamiento (entanglement) entre juicios de hecho y juicios de valor. Por ejemplo, el proceso de "salinización de los suelos" implica no sólo un juicio de hecho sobre la realidad objetiva, sino también una postura ético-política acerca de las implicancias de dicho proceso para el medio ambiente y la producción de alimentos en un sistema socioagroambiental. En los problemas complejos no es posible separar el componente "fáctico" (descriptivo-explicativo) del componente "axiológico" (ético-político).

Los problemas complejos son experiencias de la vida social que se juzgan como problemáticas porque afectan la vida misma (de los seres humanos y de la naturaleza). En el límite, un problema complejo es una situación indeseable o intolerable en términos éticos. El estudio teórico y empírico de los problemas complejos demanda una reflexividad axiológica para explicitar los aspectos éticos y políticos que intervienen en el proceso de concepción, observación y objetivación de un problema complejo. La problematización de la dimensión axiológica puede sintetizarse en el siguiente interrogante ¿por qué y para quién investigar un problema complejo?

\subsection{La dimensión práctica de los problemas complejos}

La investigación de problemas complejos articula dos principios: 'investigar para conocer' e 'investigar para actuar y transformar'. Efectivamente, un problema complejo es una situación juzgada como no deseable (ecológicamente, éticamente, socialmente, humanamente) en función de ciertos valores. De modo tal que un problema complejo entrelaza dos imperativos: un imperativo epistémico y un imperativo práctico. El primero plantea la necesidad de explicar y comprender un problema complejo, es decir, elaborar un diagnóstico riguroso tanto sobre el proceso de estructuración del sistema observado (su historia) como sobre la organización y comportamiento actual del sistema (el presente). El segundo plantea el desafío de actuar sobre el sistema para transformarlo y hacer que evolucione hacia una situación (social, ecológica, ética) más deseable (el futuro). De modo tal que un problema complejo entrelaza tres tiempos: pasado, presente y futuro.

Este abordaje epistémico y práctico de los problemas complejos conforma lo que Oscar Varsavsky (1975 y 1982) denominó un enfoque constructivo, puesto que su finalidad estratégica es transformar un problema complejo en una situación más deseable. La pregunta crucial es ¿más deseable para quién?, ¿quién decide y define qué es lo 
deseable? Para problematizar esta cuestión, proponemos distinguir tres lógicas del enfoque constructivo: lo deseable, lo posible y lo probable.

- La lógica de lo deseable implica la construcción de un modelo de futuro, es decir una representación expectativa del porvenir ¿cómo deseamos que esta situación experimentada como problemática sea en el futuro? La construcción de un modelo de futuro implica explicitar finalidades y valores. Mientras que una finalidad especifica la meta u objetivo que se desea alcanzar en el futuro; los valores son necesarios para elegir y decidir entre finalidades que son evaluadas como más o menos deseables. Un modelo de futuro es un concepto ético-político y un tipo particular de modelo normativo. La pregunta crucial es ¿de quién son los valores tomados en cuenta en la concepción y construcción de un modelo de futuro? Este interrogante permite distinguir entre los modelos top-down construidos de modo jerárquico o descendente por los gestores, directivos, decisores, planificadores, técnicos o investigadores; y los modelos bottom-up construidos de modo emergente y participativo con una multiplicidad de actores involucrados en la problemática.

- La lógica de lo posible implica la construcción de dos tipos de modelo: los modelos diagnósticos y los modelos posibilísticos. Los primeros se orientan a explicar la evolución histórica y la estructura actual de un sistema. Esto implica responder, por un lado, ¿cómo un sistema llegó a ser lo que es?, y por el otro, ¿cómo está organizado, cómo funciona y cómo se comporta en la actualidad? Por otro lado, los modelos posibilísticos se orientan a responder interrogantes del tipo: ¿qué podría suceder y no suceder en un sistema dada su organización actual? ¿cómo podría evolucionar un sistema en el futuro? Los modelos posibilísticos permiten explorar hipótesis del tipo what if? y por lo tanto resultan útiles para visibilizar alternativas, valorar su factibilidad y analizar diferentes escenarios. Los modelos posibilísticos son herramientas importantes para la planificación estratégica, la gestión de problemas complejos y la toma de decisiones puesto que ayudan a elegir entre alternativas posibles en función de los modelos de futuro construidos.

- La lógica de lo probable es característica de los modelos estadísticos generalmente construidos con una finalidad predictiva y basados en el cálculo de la confianza de una probabilidad.

En resumen, un enfoque constructivo de problemas complejos implica un proceso de sucesivas modelizaciones: un momento normativo orientado a la construcción de modelos de futuro; un momento explicativo orientado a la elaboración de modelos diagnóstico; un momento estratégico orientado a la producción de modelos posibilísticos para la visibilización y análisis de factibilidad de distintas alternativas; y finalmente, un momento tácticooperacional, orientado a intervenir prácticamente sobre el sistema para transformarlo.

\subsection{La dimensión epistémica de los problemas complejos}

La caracterización epistémica de los problemas complejos puede ser elaborada a partir de la conceptualización que Rolando García (2006) desarrolla respecto de los sistemas complejos. Sin embargo, aquí se propone distinguir entre la noción de problema complejo y de sistema complejo que García no realiza. Por un lado, un problema complejo remite a la constitución de una experiencia problematizada en la cual se encuentran entrelazados aspectos epistémicos, éticos y prácticos; mientras que, por otro lado, un sistema complejo es un modelo de un problema complejo. De modo tal que a partir de un mismo problema complejo pueden construirse distintos modelos, es decir, diferentes sistemas complejos.

Hecha esta distinción, los problemas complejos pueden ser caracterizados a través de los siguientes atributos epistémicos: 
- Múltiples procesos interrelacionados que pertenecen a distintas disciplinas. Por ejemplo, en un sistema socioagroambiental intervienen factores físicos-biológicos, ambientales, tecnológicos, productivos, socioeconómicos, jurídico-normativos.

- Interacciones entre múltiples actores sociales, políticos, económicos.

- Múltiples escalas espaciales (local, regional, global) y temporales (corto, mediano y largo plazo).

- Múltiples niveles de organización: relación no lineal entre niveles micro, meso y macro de un sistema complejo.

- Múltiples consecuencias: económicas, ecológicas, políticas, económicas, éticas.

Esta conceptualización de los problemas complejos guarda relación con lo que Warren Weaver denominó -en un trabajo pionero- problemas de complejidad organizada en los que "se encuentran involucrados una cantidad considerable de factores interrelacionados en un todo orgánico" (Weaver, 1948, p. 3) . Frente a este tipo de problemas Weaver distinguía, además, lo que denominó problemas de simplicidad y problemas de complejidad desorganizada. Mientras los primeros refieren a fenómenos que pueden ser analizados a partir de la relación entre pocas variables mediante modelos mecánicos (por ejemplo la física clásica); los segundos involucran un número elevado de variables o elementos y pueden ser estudiados por modelos estadísticos (por ejemplo la termodinámica).

Los problemas de complejidad organizada no pueden ser estudiados por modelos mecánicos ni por modelos estadísticos, sino que requieren de modelos sistémicos. Así, un problema complejo puede ser caracterizado por los atributos que habitualmente se emplean para describir la estructura y dinámica de los sistemas complejos: la autoorganización (Ashby, 1962; Foerster, 1960) , la emergencia (Holland, 1998; Johnson, 2001), la no linealidad (Prigogine y Stengers, 1983), la sensibilidad a las condiciones iniciales (Briggs y Peat, 1989; Prigogine, 1999), el comportamiento adaptativo (Holland, 1995; Miller y Page, 2007), entre otros. Un sistema complejo es un conjunto de elementos interrelacionados cuya interacción dinámica en el tiempo produce un comportamiento agregado emergente a nivel macro cuyas propiedades y características funcionales no pueden deducirse linealmente del estudio analítico de las partes a nivel micro. Es por esta razón que los problemas complejos pueden ser investigados a través de los métodos de modelización y simulación de las ciencias de la complejidad $\underline{5}$.

\subsection{La dimensión metodológica de los problemas complejos}

El carácter sistémico de los problemas complejos plantea consecuencias metodológicas para su estudio. Un problema complejo corresponde a lo que Herbert Simon (1973) conceptualizó como sistemas no descomponibles. En estos sistemas, los elementos y procesos que los componen se determinan mutuamente y, en consecuencia, no pueden ser separados para ser estudiados de manera aislada e independiente. Además, los componentes de un problema complejo pertenecen al dominio de distintas disciplinas. Desde el punto de vista metodológico, la complejidad de un problema está ligada a la imposibilidad de comprenderlo sistémicamente desde una disciplina particular o mediante la simple adición de estudios disciplinarios (García, 2006) .

Esta concepción de problemas complejos plantea implicancias metodológicas sobre el tipo de investigación necesaria para su estudio. Siguiendo el trabajo de Rolando García (2006), puede argumentarse que los problemas complejos requieren de una metodología de investigación interdisciplinaria. Esta metodología no supone la anulación ni la fusión de las disciplinas, puesto que el conocimiento disciplinario especializado es necesario pero insuficiente para el estudio y el diagnóstico integrado de problemas complejos. Esto permite establecer una diferencia sustantiva con las investigaciones transdisciplinarias (Nicolescu et al., 1994; Vilar, 1997) , la integración de disciplinas (Wallerstein, 1996) o la formación de generalistas sistémicos (Bertalanffy, 1976) . Lo que caracteriza la metodología interdisciplinaria propuesta por García es la integración de enfoques disciplinarios al comienzo de la investigación para construir un problema común y un marco conceptual compartido. La 
interdisciplina es un proceso que articula fases de integración y diferenciación entre las disciplinas y, por lo tanto, no es el resultado espontáneo de la constitución de equipos multidisciplinarios. Esta precisión permite establecer otra diferencia sustantiva con lo que habitualmente se denominan investigaciones "multidisciplinarias" en las que "se suelen sumar los aportes que cada investigador realiza desde su disciplina particular en torno a una problemática general que puede ser analizada desde diferentes perspectivas” (García, 2006, y 33) . Con todo, la investigación interdisciplinaria es un proceso y no un acto de coordinación de resultados de estudios disciplinarios.

\subsection{Síntesis provisional del concepto de problema complejo}

Un problema complejo es un metasistema que incluye múltiples puntos de vista de distintos sistemas observadores sobre una experiencia común que busca ser conocida y transformada porque es evaluada como no deseable. Esos sistemas observadores comprenden especialistas de distintas disciplinas, actores sociales involucrados en la problemática, políticos, planificadores y tomadores de decisión. Esa experiencia problemática constituye un sistema observado que surge de la objetivación producida por la articulación de múltiples puntos de vista. Dicho sistema observado puede ser conceptualizado como un sistema complejo y estudiado por una metodología interdisciplinaria. La expresión problema complejo es el metasistema que articula el sistema observador y el sistema observado. Mientras que las ciencias de la complejidad ofrecen técnicas y herramientas para objetivar la complejidad del sistema observado, el pensamiento complejo ofrece una estrategia reflexiva para modelizar un meta-punto de vista que permita al sistema observador, observar su observación, objetivar su modo de objetivación, pensar su pensamiento, concebir su concepción.

\section{Un modelo epistemológico para la investigación empírica de los sistemas de pensamiento}

El concepto de paradigma elaborado por Edgar Morin es una herramienta teórica útil para construir un meta-punto de vista reflexivo y autocrítico de un sistema de pensamiento. Sin embargo, la obra de Morin presenta una limitación metodológica por cuanto no ofrece una estrategia para la investigación empírica de los paradigmas. De modo tal que la pregunta crucial es ¿cómo investigar empíricamente un paradigma y cómo modelizar un metapunto de vista de un sistema observador que pueda ayudarlo a observarse y pensarse a sí mismo? Aquí se propone un modelo epistemológico del pensamiento complejo (MEPC) como respuesta posible a este problema. Este modelo plantea el estudio empírico cualitativo y cuantitativo de las creencias científicas como estrategia para modelizar un paradigma, esto es, los principios organizadores de un sistema de pensamiento. Este modelo ha sido construido y puesto a prueba en una investigación empírica sobre el sistema de creencias de las ciencias de la complejidad y la simulación social (cita removida para garantizar el anonimato de la evaluación).

La argumentación de esta sección está organizada del siguiente modo. Primero, se precisa el concepto de sistema de creencias científicas (apartado 4.1) para luego describir los sistemas de creencias como redes de proposiciones (apartado 4.2). Tras este andamiaje, se aborda la sociogénesis comunicativa de las creencias científicas (apartado 4.3). Seguidamente, se elabora una relación conceptual entre los términos de paradigma, marco epistémico y actitud para abordar la complejidad organizacional de los sistemas de creencias (apartado 4.4), lo que permite proponer una estrategia metodológica para la investigación empírica de los paradigmas (apartado 4.5). Finalmente, se ilustra la aplicación de este modelo al caso de las ciencias de la complejidad y la simulación social (apartado 4.6).

\subsection{El sistema de creencias científicas}

Conforme a la idea del pensamiento como proceso de modelización, según fue previamente conceptualizado, las creencias científicas son representaciones sociales compartidas por los miembros de una comunidad de investigación. Por consiguiente, las creencias científicas constituyen una forma de cognición social, esto es, modelos mentales de carácter social. Un sistema de creencias científicas es una estructura compleja de creencias heterogéneas sobre las múltiples dimensiones de las prácticas científicas y su relación con la sociedad. Las 
principales dimensiones de las creencias científicas comprenden:

- Creencias ontológicas: representaciones sobre los objetos de conocimientos y creencias sobre la naturaleza de la realidad, qué es la realidad y cómo podemos conocerla.

- Creencias epistémicas: concepciones relativas a qué es y qué debe ser el conocimiento científico, y la idea de ciencia que se acepta como válida.

- Creencias metodológicas: concepciones relativas a los métodos e instrumentos para construir conocimiento.

- Creencias lógico-cognitivas: concepciones relativas a las estrategias cognitivas para construir conocimiento, representaciones sobre la propia estrategia de pensamiento y los principios de conocimiento.

- Creencias sociales: concepciones relativas a la relación ciencia-sociedad, ideas sobre cómo la sociedad condiciona el trabajo científico y sus consecuencias sociales, creencias normativas acerca de cómo debería ser la relación entre la ciencia y la sociedad, concepciones acerca de la responsabilidad social de la ciencia y del científico.

- Creencias axiológicas: concepción acerca del rol de los valores (éticos, sociales, políticos) en el proceso de construcción de conocimiento científico.

- Creencias antropológicas: concepciones sobre el rol del sujeto de conocimiento.

Un sistema de creencias es un conjunto organizado de ideas, creencias, representaciones, valores y actitudes de una comunidad científica. Como construcciones sociocognitivas, las creencias científicas son un tipo de conocimiento socialmente producido y compartido que permite estructurar una visión funcional del mundo. En este sentido, las creencias científicas constituyen esquemas compartidos de acción y comunicación que permiten la estructuración práctica de la vida científica. En consecuencia, las creencias científicas juegan un rol crucial en la organización de las prácticas científicas, puesto que permiten entenderse acerca de lo que se hace, cómo se lo hace y con qué se lo hace.

Las creencias científicas constituyen la noosfera del pensamiento científico $\underline{\underline{6}}$, en el sentido en que los científicos razonan en base a sus creencias. Asimismo, las creencias intervienen en la formación de modelos mentales con los cuales los científicos elaboran esquemas interpretativos de los contextos prácticos en los que actúan. En conclusión, las creencias científicas, socialmente construidas y compartidas, brindan el marco sociocognitivo del pensamiento científico.

\subsection{Los sistemas de creencias como redes de proposiciones}

La psicología cognitiva plantea que las creencias se ubican en una dimensión de la mente llamada memoria semántica, consistente en un tipo de memoria a largo plazo que permite almacenar representaciones mentales permanentes (Best, 2002, pp. 116-119; Bruning et al., 2005, pp. 46-52) ${ }^{7}$. De acuerdo con van Dijk (1999, p. 48) las creencias sociales son representaciones mentales compartidas alojadas en la memoria social. Conforme estos aportes, puede afirmarse que las creencias científicas se ubican en una memoria semántica de tipo social. Por consiguiente, las creencias científicas son construcciones mentales, sociales y compartidas.

Las ciencias cognitivas y la psicología cognitiva de la memoria han propuesto diversos modelos para describir el modo en que se representan y organizan los contenidos de la memoria semántica. Ross Quillian (1968) propuso uno de los primeros modelos según el cual la información se organiza en redes de proposiciones. Una proposición consiste en la vinculación entre dos nodos o conceptos mediante una relación significativa (Hernandez Forte, 
2005, p. 61) . La proposición es la unidad mínima de procesamiento de información de la memoria (Gagné, 1991, p. 77) . Las proposiciones "permiten independizar las expresiones léxicas, gramaticales y sintácticas de las oraciones del lenguaje natural, representando su significado en un código semántico” (Rodríguez, 2010, p. 220) . Por esta razón, las proposiciones no son equivalentes a las frases o las oraciones. La diferencia estriba en que "las palabras, sintagmas y oraciones representan formas de comunicar ideas, mientras que las proposiciones representan las ideas propiamente dichas” (Gagné, 1991, p. 82). Desde esta perspectiva, las proposiciones se articulan constituyendo redes proposicionales que permiten representar significativamente el contenido almacenado en la memoria semántica, por lo que la memoria semántica tiene una estructura reticular (Cabeza, 1987, pp. 84-85) .

Desde este enfoque, las creencias científicas pueden ser descriptas mediante redes significativas de proposiciones alojadas en la memoria social de un grupo (van Dijk, 1999, pp. 39-40) . En consecuencia, las creencias científicas no son objetos mentales discretos, aislados e independientes unos de otros, sino que conforman un conjunto reticular organizado de proposiciones.

\subsection{La sociogénesis comunicativa de las creencias científicas}

Las creencias científicas son el resultado emergente de prácticas sociales cognitivas. Las creencias se elaboran a través de un proceso práctico (comunicativo, discursivo y simbólico) en el que se articula la actividad mental del individuo y la dimensión social del grupo. Se acuña el concepto de sociogénesis de las creencias científicas para dar cuenta del proceso sociocognitivo a través del cual las creencias son construidas y transformadas. El vínculo crucial entre las creencias científicas socialmente compartidas y los modelos mentales individuales tiene que ser concebido a partir de la dimensión comunicacional que supone el proceso de esquematización de un modelo mental. Efectivamente, los conceptos de modelo mental y esquematización permiten conectar la cognición y el pensamiento del sujeto individual con la situación empírica en la cual los individuos dialogan y se comunican a través del discurso basado en el lenguaje natural. De esta manera, el diálogo cobra relevancia en tanto proceso práctico en el que se articulan de modo indisociable los componentes sociales y cognitivos de las creencias científicas.

Así, las categorías de diálogo e interacción socioverbal propuestas por Voloshinov (1976) devienen categorías epistemológicas centrales para problematizar la sociogénesis de las creencias científicas. En la práctica científica concreta, los investigadores se relacionan a través de prácticas interdiscursivas en las cuales se ponen en juego las esquematizaciones de modelos mentales formados por las creencias científicas. La interdiscursividad es un proceso dinámico y controversial por el cual los científicos pueden arribar a consensos (creencias compartidas) o desacuerdos (creencias contrarias) sobre la situación práctica en la que actúan. Así, las creencias personales movilizadas en la elaboración de modelos mentales, "pueden ser vistas como compartidas por otros y, por lo tanto, se generalizan como creencias sociales” (van Dijk, 1999, p. 115. El énfasis es nuestro) .

Es posible establecer una articulación conceptual entre, por un lado, el proceso de generalización de las creencias socialmente compartidas, sugerido por van Dijk y, por otro lado, los mecanismos de abstracción y generalización propuestos por la epistemología genética para dar cuenta de la psicogénesis de las estructuras formales del pensamiento (García, 1997, pp. 47-53) .

Siguiendo el razonamiento de Castorina (2007, pp. 167-168), los mecanismos de abstracción y generalización, concebidos por Jean Piaget a nivel de la lógica operatoria, pueden ser extendidos al análisis de la lógica natural desarrollada por Blaise Grize. Estos razonamientos permiten elaborar una hipótesis teórica sobre la sociogénesis de las creencias científicas: las creencias científicas se construyen y transforman a través de la abstracción y generalización de las esquematizaciones de los modelos mentales emergentes de la práctica interdiscursiva entre los científicos. Por consiguiente, las prácticas interdiscursivas constituyen la arena de adquisición, construcción y transformación de las creencias científicas. Así como para la epistemología genética el pensamiento es la organización de acciones interiorizadas (Piaget, 1973, pp. 89-92), las creencias científicas son la organización de las prácticas interdiscursivas interiorizadas. 
4.4. La complejidad organizacional de los sistemas de creencias: paradigma, marco epistémico y actitudes

Un paradigma es la pauta que conecta conjuntos heterogéneos de creencias. El paradigma es un concepto organizacional que se emplea para caracterizar el tipo de relaciones establecidas entre redes de creencias heterogéneas. Por esta razón, un paradigma carece de formulación explícita y no debe ser confundido con una teoría o corpus de conocimiento. Más bien, un paradigma comprende "las relaciones fundamentales de exclusión y/o de asociación entre conceptos primarios, es decir, las alternativas y asociaciones preliminares [...] que controlan y orientan todo saber, todo pensamiento y, por ello, toda acción” (Morin, 1977, p. 430) . Los paradigmas constituyen los principios organizadores del pensamiento que regulan las "operaciones de unión (conjunción, inclusión, implicación) y de separación (diferenciación, oposición, selección, exclusión)” (Morin, 1999, p. 26) entre ideas, creencias o conceptos. En consecuencia, un paradigma es endógeno al pensamiento, a la teoría, al razonamiento, al discurso; funciona como un principio generativo que modula la organización del pensamiento y de los razonamientos. Así, un paradigma carece de existencia propia (como cosa o entidad sustancial) y sólo tiene una existencia virtual. En consecuencia, un paradigma sólo existe en la medida en que es generado y regenerado por la práctica, por el pensamiento, por el discurso. Es así como un paradigma "depende de la realidad fenoménica que genera y precisa de esta realidad fenoménica para ser regenerado” (Morin, 1991, pp. 236-237) .

Por otro lado, un marco epistémico es un conjunto de creencias organizadas en virtud de un paradigma. El término fue acuñado por la epistemología genética para designar un sistema de pensamiento tácito que constituye una visión del mundo y condiciona las teorizaciones en diversas disciplinas sin determinar su contenido (García, 2000; Piaget y García, 2008) . De esta manera, es importante destacar que un sistema de creencias científicas, en un determinado contexto espacio-temporal, puede estar compuesto por diversos marcos epistémicos. Más aún, marcos epistémicos rivales pueden coexistir en un sistema de creencias científicas, expresando distintas concepciones de realidad, conocimiento, ciencia, métodos de investigación, etcétera. Así, por ejemplo, dos grupos de investigación de una misma disciplina pueden manifestar creencias ontológicas y axiológicas contrarias, y compartir, no obstante, creencias metodológicas. Esto muestra la complejidad de los modos de articulación y oposición entre los marcos epistémicos que constituyen un sistema de creencias. En suma, los paradigmas refieren al modo en que se relacionan las creencias que constituyen un marco epistémico.

Para investigar empíricamente los paradigmas que organizan un sistema de creencias científicas, se requiere de un dispositivo conceptual que haga de interfaz entre el nivel de las creencias científicas y el marco epistémico. Dicho de otro modo, desde un punto de vista teórico, se requiere un concepto que permita dar cuenta cómo se agrupan y relacionan las creencias al interior de un marco epistémico. El concepto de actitud es una categoría teórica empleada para describir racimos de creencias científicas que integran un marco epistémico. Las actitudes son “conjuntos específicos, organizados, de creencias socialmente compartidas” (van Dijk, 1999, p. 65) . Más específicamente, las actitudes consisten en "creencias evaluativas socialmente compartidas” (van Dijk, 1999, p. 55) . Una creencia evaluativa es una proposición con la que uno puede estar de acuerdo o no. En suma, las actitudes expresan grados de acuerdo sobre un conjunto específico de creencias. Por este motivo, un racimo de creencias que forma una actitud se organiza en virtud de un tema, por ejemplo: creencias sobre el rol de los valores en la ciencia, creencias sobre la naturaleza de la realidad (creencias ontológicas), etcétera.

En síntesis:

- Un sistema de creencias científicas puede estar organizado por uno o varios marcos epistémicos y paradigmas.

- Un marco epistémico está compuesto por actitudes interrelacionadas y cada actitud está conformada por racimos organizados de creencias.

- Cada actitud o racimo de creencias constituye una red proposicional que forma parte de la memoria social de un grupo. 
- Un paradigma es la pauta organizacional que conecta los racimos de creencias que constituyen un marco epistémico.

- Los paradigmas son un principio organizacional común al marco epistémico, a los sistemas de creencia y a los sistemas de pensamiento.

- La investigación empírica de las creencias científicas constituye una estrategia para el estudio de los paradigmas y la organización de los sistemas de pensamiento.

\section{5. ¿Cómo investigar empíricamente un paradigma?}

Los métodos cualitativos y cuantitativos pueden ser empleados para construir evidencia empírica de las creencias científicas y modelizar la organización de un sistema de pensamiento. En primer lugar, los métodos cualitativos resultan fundamentales para analizar la lógica discursiva en la que se expresa el pensamiento natural de los científicos. Específicamente, las técnicas de conversación, tales como la entrevista en profundidad y los grupos focales, constituyen un recurso metodológico valioso para producir evidencia empírica de los discursos científicos. Las prácticas discursivas constituyen el terreno en el que emergen formas de razonamiento, creencias y actitudes. Asimismo, la conversación brinda la posibilidad de indagar cómo el científico piensa su propio modo de pensamiento y, así, inferir estrategias metacognitivas.

En segundo lugar, las técnicas psicométricas de medición de actitudes, como las escalas Likert (1932), resultan útiles para la producción de evidencia empírica cuantitativa de las creencias científicas. Una escala de medición de actitudes es un conjunto de ítems. Cada ítem es un indicador empírico de la actitud que se pretende medir. Los ítems se redactan "en forma de opiniones con las que se puede estar o no de acuerdo. Una opinión es una actitud verbalizada, y a través de las opiniones podemos inferir la actitud subyacente” (Morales Vallejo et al., 2003, p. 50).

Epistemológicamente, puede establecerse un puente teórico entre el concepto de creencia científica y las técnicas de medición de actitudes. En efecto, se ha argumentado que las creencias son proposiciones y las actitudes son racimos interrelacionados de creencias, es decir, redes de proposiciones. De este modo, cada ítem de una escala Likert puede considerarse como una proposición y, por lo tanto, como una creencia evaluativa. El conjunto de ítems que conforman una escala puede interpretarse teóricamente como un racimo interrelacionado de creencias evaluativas socialmente compartidas. Por esta vía, las técnicas escalares constituyen una estrategia para investigar empíricamente los sistemas de creencias científicas. Teóricamente, parece importante subordinar el empleo de la técnica de medición de actitudes al análisis cualitativo del discurso científico. En efecto, el análisis cualitativo es verdaderamente crucial para inferir y conceptualizar las creencias y actitudes a ser medidos cuantitativamente. Dicho de otro modo, sólo a posteriori del análisis cualitativo del discurso pueden especificarse cuántas escalas y qué ítems son necesarios para modelizar la complejidad de un marco epistémico. El análisis cualitativo es la base metodológica para la modelización cuantitativa de las creencias científicas.

Además, las técnicas de análisis estadístico multivariado constituyen una vía para modelizar la organización de un sistema de creencias científicas; en particular, se enfatiza la importancia del análisis factorial exploratorio (AF) y la regresión lineal múltiple. Por un lado, el AF resulta útil para explorar la estructura subyacente a los ítems que conforman una escala y, por consiguiente, transformar múltiples variables observables a un número reducido de variables latentes. Metodológicamente, el AF permite construir índices factoriales, mientras que teóricamente posibilita conceptualizar los constructos identificados, refinando el análisis cualitativo. Por otro lado, el análisis de regresión múltiple nos ayuda a comprender la relación entre distintas actitudes y racimos de creencias y, por lo tanto, a modelizar el principio organizador que estructura un sistema de creencias científicas.

La articulación complementaria entre el análisis factorial y el de regresión lineal múltiple, constituye una estrategia metodológica para comprender y explicar la magnitud y densidad de la trama de relaciones entre las creencias científicas. En otros términos, el recurso de las técnicas multivariadas permite cuantificar el complejo 
entramado de la organización reticular de las creencias científicas. Por esta razón, el análisis estadístico permite dar cuenta del paradigma o pauta organizacional que conecta actitudes o racimos de creencias que conforman un marco epistémico. En consecuencia, el componente cuantitativo de la estrategia metodológica permite la operacionalización estadística del constructo de marco epistémico, gestado en la epistemología genética de Jean Piaget y Rolando García y del constructo de paradigma elaborado en el marco de la obra de Edgar Morin.

\subsection{El sistema de creencias científicas de las ciencias de la complejidad}

Habiendo reseñado el modelo epistemológico del pensamiento complejo (MEPC), el objetivo de este apartado es ilustrar sintéticamente la aplicación empírica de este modelo en una investigación sobre los sistemas de pensamiento. Este modelo ha sido testeado en una investigación empírica cualitativa y cuantitativa sobre el sistema de creencias científicas de las ciencias de la complejidad (cita removida para garantizar el anonimato de la evaluación). El objetivo de esta investigación fue comprender los paradigmas y marcos epistémicos que estructuran las prácticas de construcción de conocimiento de las ciencias de la complejidad.

El diseño cualitativo comprendió 53 entrevistas en profundidad con investigadores del campo de los sistemas complejos y de la simulación social, pertenecientes a siete países de América Latina y de Europa. El diseño de la investigación cuantitativa se apoyó en los resultados del análisis cualitativo de los discursos científicos. Se construyó una batería de 18 escalas Likert y un banco de 404 ítems, con la finalidad de medir empíricamente las creencias científicas de las ciencias de la complejidad.

El trabajo de campo cuantitativo se realizó por medio de una "Encuesta Global sobre prácticas de investigación en sistemas complejos y simulación social” aplicada a una muestra compuesta por 232 encuestados de 28 países. La modelización del sistema de creencias científicas se sustentó en el análisis cualitativo del discurso, el análisis factorial y la técnica de análisis de regresión lineal múltiple. La operacionalización estadística del modelo epistemológico del pensamiento complejo (MEPC) se realizó mediante el desarrollo de 59 índices sobre creencias científicas y la construcción de 22 modelos de regresión. De este modo, fue posible reconstruir la estructura de racimos de creencias que organizan los marcos epistémicos de las ciencias de la complejidad y los principios paradigmáticos que articulan sus relaciones. Una documentación completa del análisis puede encontrarse en (cita removida para garantizar el anonimato de la evaluación).

La encuesta utilizó diez escalas con 111 ítems del banco de 404 ítems, para limitar la extensión del cuestionario. La Tabla 1 presenta el análisis de confiabilidad de las diez escalas Likert empleadas para modelizar el sistema de creencias científicas de las ciencias de la complejidad:

\section{Tabla 1. Análisis de confiabilidad de las escalas Likert}

\begin{tabular}{|c|c|c|c|c|c|}
\hline $\mathbf{N}^{\mathbf{o}}$ & Nombre de la Escala & $\begin{array}{l}\text { Cant. Ítems } \\
\text { originales }^{8}\end{array}$ & $\begin{array}{l}\text { Cant. Ítems } \\
\text { definitivos }^{9}\end{array}$ & $\begin{array}{l}\text { Correlación } \\
\text { inter-ítem }{ }^{10}\end{array}$ & $\begin{array}{l}\text { Coeficiente } \\
\text { Alfa }{ }^{11}\end{array}$ \\
\hline 1 & $\begin{array}{l}\text { Estrategias cognitivas del } \\
\text { pensamiento complejo }\end{array}$ & 12 & 12 & 197 & ,746 \\
\hline 2 & $\begin{array}{l}\text { Operaciones cognitivas } \\
\text { simplificadoras }\end{array}$ & 12 & 12 & 208 & ,759 \\
\hline 3 & Finalidad de la Ciencia & 12 & 8 & 291 & ,767 \\
\hline 4 & Rol de los Valores & 16 & 10 & 346 & ,841 \\
\hline 5 & Responsabilidad Científica & 12 & 9 & 295 & ,790 \\
\hline 6 & Concepción de Realidad & 12 & 6 & 294 & ,714 \\
\hline
\end{tabular}




\begin{tabular}{|l|l|c|c|c|c|}
\hline & & & & & \\
\hline 7 & Complejidad y subjetividad & 8 & $\mathbf{8}$ & $\mathbf{3 5 3}$ & $\mathbf{, 8 1 3}$ \\
\hline 8 & $\begin{array}{l}\text { Ontología de los sistemas } \\
\text { complejos }\end{array}$ & 7 & $\mathbf{7 0 2}$ & $\mathbf{, 8 2 5}$ \\
\hline 9 & $\begin{array}{l}\text { Concepciones de } \\
\text { complejidad }\end{array}$ & 14 & $\mathbf{1 2}$ & $\mathbf{3 3 5}$ & $\mathbf{, 8 5 8}$ \\
\hline & $\begin{array}{l}\text { Estrategias de modelado de } \\
\text { fenómenos sociales } \\
\text { complejos }\end{array}$ & 6 & Escala eliminada por falta de validez \\
\hline & Total ítems & 111 & $\mathbf{8 4}$ & & \multicolumn{2}{|}{} \\
\hline
\end{tabular}

El análisis factorial de las escalas Likert permitió identificar 22 constructos relevantes desde el punto de vista teórico. Para cada uno de estos constructos se realizó un análisis de confiabilidad adicional. Apoyados en el análisis factorial, se construyeron índices sobre las creencias científicas. La Figura 1 muestra una representación gráfica del análisis factorial de la escala $n^{\circ} 4$ sobre la concepción del rol de los valores en la investigación científica $\underline{12}$.

Figura 1. Análisis factorial de la escala Likert n4 "Concepción sobre el rol de los valores"
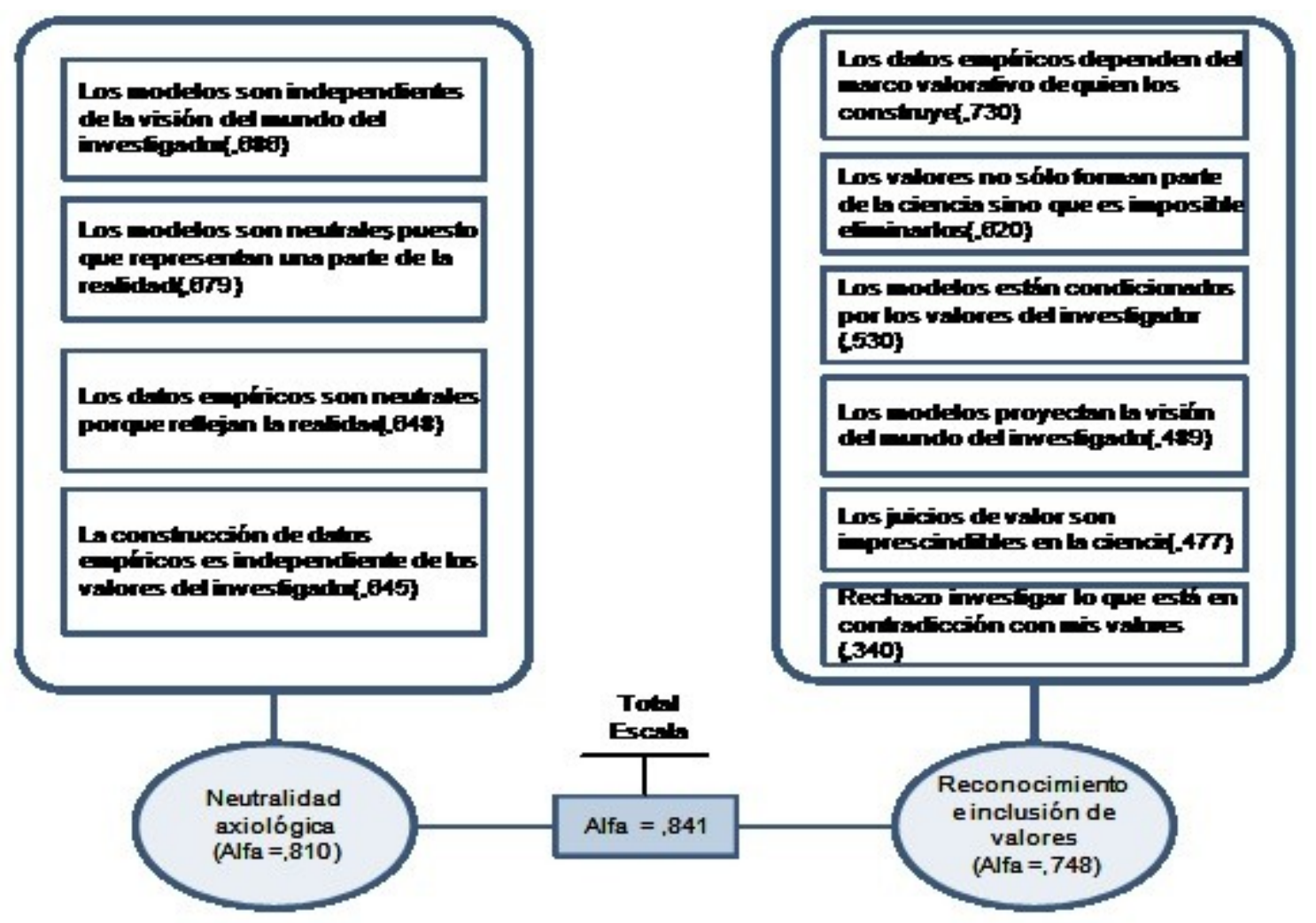

El aspecto más interesante del análisis consistió en el trabajo de modelización de las creencias científicas a través de la construcción de modelos de regresión lineal múltiple. Los veintidós modelos de regresión construidos fueron sometidos a un riguroso análisis para verificar el cumplimiento de los supuestos fundamentales del análisis de regresión (linealidad, normalidad, nula o baja multicolinealidad, ausencia de autocorrelación homocedasticidad). Estos modelos permiten reconstruir la complejidad organizacional de un sistema de creencias científicas. La Tabla 
2 muestra una síntesis de los veintidós modelos de regresión.

Tabla 2. Síntesis de los 22 modelos de regresión múltiple sobre las creencias científicas

\begin{tabular}{|c|c|c|c|c|c|c|c|c|}
\hline & $\begin{array}{l}\text { Constructo teórico } \\
\text { explicado por el modelo } \\
\text { de regresión lineal } \\
\text { múltiple }\end{array}$ & $X_{n} \underline{13}$ & $\mathbf{R}^{14}$ & $\mathbf{R}^{2} \underline{15}$ & $\mathbf{R}^{2}$ Correg. ${ }^{16}$ & $\begin{array}{l}\text { Durbin- } \\
\text { Watson } \underline{17}\end{array}$ & $\begin{array}{l}\text { Menor } \\
\text { toleranci } \\
a^{\underline{18}}\end{array}$ & $\begin{array}{l}\text { Mayor } \\
\text { FIV } \underline{19}\end{array}$ \\
\hline 1 & $\begin{array}{l}\text { Concepción de Sistemas } \\
\text { Complejos (Modelo A) }\end{array}$ & 2 & 629 & 395 & ,387 & 2,028 & ,770 & 1,299 \\
\hline 2 & $\begin{array}{l}\text { Concepción de Sistemas } \\
\text { Complejos (Modelo B) }\end{array}$ & 5 & 675 & ,456 & ,437 & 2,041 & 644 & 1,553 \\
\hline 3 & $\begin{array}{l}\text { Concepción } \\
\text { constructivista de los } \\
\text { Sistemas Complejos }\end{array}$ & 5 & 662 & ,438 & ,418 & 2,103 & 638 & 1,568 \\
\hline 4 & $\begin{array}{l}\text { Concepción realista de los } \\
\text { Sistemas Complejos }\end{array}$ & 5 & ,541 & 292 & 267 & 2,118 & 651 & 1,535 \\
\hline 5 & $\begin{array}{l}\text { Concepción sobre el rol de } \\
\text { los valores }\end{array}$ & 2 & 657 & ,432 & ,424 & 2,181 & ,760 & 1,315 \\
\hline 6 & $\begin{array}{l}\text { Neutralidad valorativa de } \\
\text { los modelos y los datos } \\
\text { (Modelo A) }\end{array}$ & 2 & ,584 & ,341 & 332 & 1,936 & ,760 & 1,315 \\
\hline 7 & $\begin{array}{l}\text { Neutralidad valorativa de } \\
\text { los modelos y los datos } \\
\text { (Modelo B) }\end{array}$ & 5 & ,662 & ,438 & ,419 & 2,035 & ,647 & 1,546 \\
\hline 8 & $\begin{array}{l}\text { Rol constructivo de los } \\
\text { valores (Modelo A) }\end{array}$ & 2 & ,589 & 347 & ,338 & 2,171 & ,761 & 1,315 \\
\hline 9 & $\begin{array}{l}\text { Rol constructivo de los } \\
\text { valores (Modelo B) }\end{array}$ & 5 & 605 & ,367 & ,344 & 2,161 & 651 & 1,535 \\
\hline 10 & $\begin{array}{l}\text { Concepción de la finalidad } \\
\text { de la ciencia (Modelo A) }\end{array}$ & 5 & ,417 & ,174 & 145 & 1,528 & 651 & 1,535 \\
\hline 11 & $\begin{array}{l}\text { Concepción de la finalidad } \\
\text { de la ciencia (Modelo B) }\end{array}$ & 3 & ,725 & ,525, & ,517 & 1,795 & ,783 & 1,277 \\
\hline 12 & Rol social de la ciencia & 10 & ,717 & ,513 & ,478 & 1,638 & ,484 & 2,066 \\
\hline 13 & $\begin{array}{l}\text { Rol epistémico de la } \\
\text { ciencia }\end{array}$ & 10 & ,569 & ,323 & ,274 & 1,718 & ,476 & 2,103 \\
\hline 14 & $\begin{array}{l}\text { Modelos simples y } \\
\text { atributos epistémicos }\end{array}$ & 4 &, 574 & ,330 & ,309 & 1,846 & ,779 & 1,283 \\
\hline
\end{tabular}




\begin{tabular}{|c|c|c|c|c|c|c|c|c|}
\hline 15 & $\begin{array}{l}\text { Modelos simples y } \\
\text { estrategias cognitivas }\end{array}$ & 3 & ,504 & ,254 & ,236 & 1,932 & 848 & 1,179 \\
\hline 16 & $\begin{array}{l}\text { Modelos simples: } \\
\text { estrategias cognitivas y } \\
\text { atributos epistémicos }\end{array}$ & 7 & ,725 & ,526, & 499 & 1,797 & 751 & 1,332 \\
\hline 17 & $\begin{array}{l}\text { Modelos simples y } \\
\text { concepción de ciencia, de } \\
\text { sujeto y de realidad }\end{array}$ & 3 & ,291 & 085 & ,062 & 1,843 & ,793 & 1,260 \\
\hline 18 & $\begin{array}{l}\text { Modelos sociales } \\
\text { participativos y atributos } \\
\text { epistémicos }\end{array}$ & 5 & 627 & 393 & 369 & 1,981 & 915 & 1,093 \\
\hline 19 & $\begin{array}{l}\text { Modelos sociales } \\
\text { participativos y estrategias } \\
\text { cognitivas }\end{array}$ & 5 & ,484 & 235 & 205 & 2,007 & ,789 & 1,267 \\
\hline 20 & $\begin{array}{l}\text { Modelos sociales } \\
\text { participativos: estrategias } \\
\text { cognitivas y atributos } \\
\text { epistémicos }\end{array}$ & 10 & ,674 & ,454 & 409 & 1,983 & ,759 & 1,318 \\
\hline 21 & $\begin{array}{l}\text { Modelos sociales } \\
\text { participativos: concepción } \\
\text { de ciencia, de sujeto y de } \\
\text { realidad }\end{array}$ & 3 & 450 & 202 & 183, & 2,058 & ,793 & 1,260 \\
\hline 22 & $\begin{array}{l}\text { Concepción de modelos } \\
\text { complejos }\end{array}$ & 5 & 603 & ,364 & 338 & 2,173 & 859, & 1,164 \\
\hline
\end{tabular}

Se han empleado mapas conceptuales para la representación gráfica de las relaciones estadísticas analizadas por los modelos de regresión. La modelización de redes de creencias con mapas conceptuales permite resumir gráficamente los resultados de dos, tres o incluso más modelos de regresión múltiple en un diagrama unificado, presentando una visión sintética de la estructura reticular de las creencias científicas. Con el objeto de producir un mapa fácilmente interpretable, se establecieron distinciones cromáticas y geométricas de los nodos de la red.

\section{Tabla 3. Distinción cromática y geométrica para la modelización de las creencias científicas}

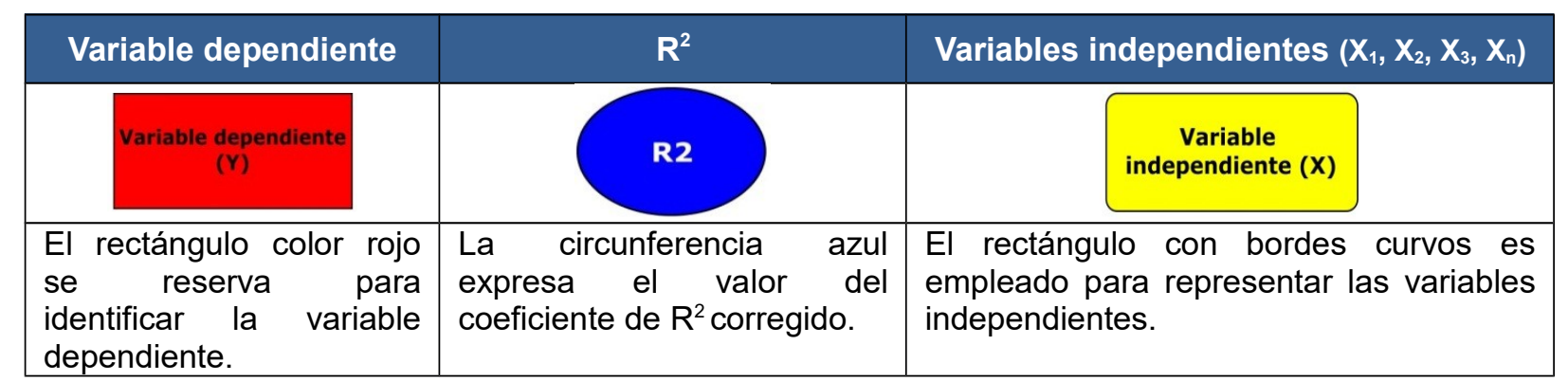

Aquí brindamos un breve ejemplo de un modelo visual de un marco epistémico construido por tres racimos de creencias: creencias axiológicas, creencias ontológicas y creencias antropológicas. El análisis empírico ha permitido establecer que las concepciones acerca del rol de los valores en ciencia (creencias axiológicas) están determinadas simultáneamente por la concepción de realidad (creencias ontológicas) y por la concepción del lugar 
del sujeto en la construcción de conocimiento (creencias antropológicas). Se ha elaborado un mapa conceptual para ilustrar este análisis por medio de la articulación de tres modelos de regresión (Ver Figura $2 \underline{20}$ ).

Figura 2. Un modelo de un marco epistémico

El mapa conceptual integra tres modelos de regresión (Modelos $N^{\circ}$ 5, 6 y 8 de la Tabla 2)

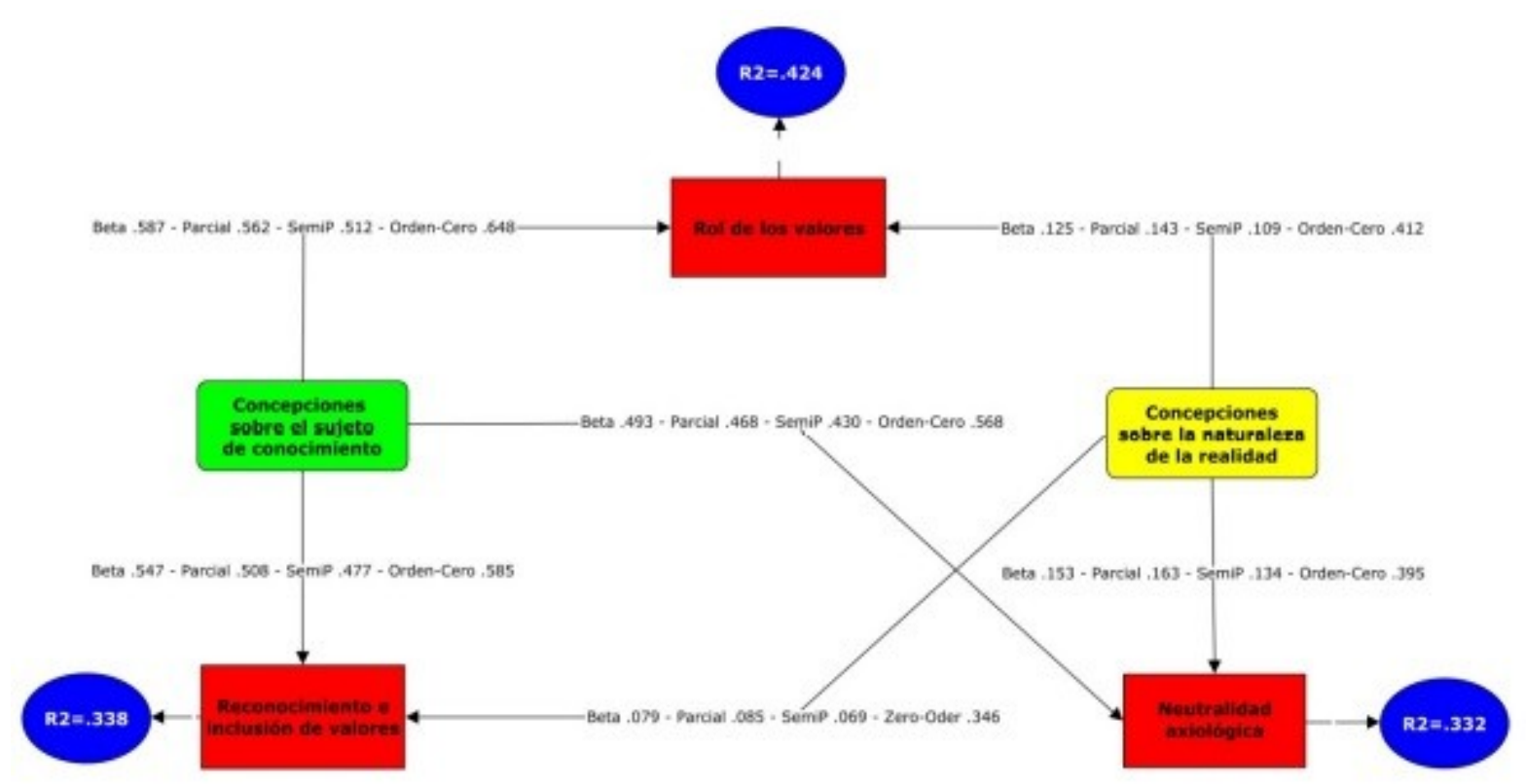

Señalemos algunas breves observaciones. La concepción de realidad y la concepción de sujeto explican el 42.4\% de la variación de las concepciones axiológicas (Modelo $\mathrm{N}^{\circ}$ 5). Sin embargo, la concepción de sujeto juega un rol notablemente más preponderante en relación a la concepción de realidad (Beta .587 y .125 respectivamente). Más aún, se destaca que las concepciones de sujeto y de realidad explican el 33.2\% de la variación en la concepción que sostiene la neutralidad axiológica (Modelo $\mathrm{N}^{\circ}$ 6) y el 33.8\% de la concepción inclusiva de los valores (Modelo $\mathrm{N}^{\circ}$ 8). Las creencias antropológicas contribuyen de modo similar a la explicación de las dos concepciones axiológicas, aunque la influencia es relativamente mayor en la relación entre sujeto e inclusión de valores $\underline{21}$. Inversamente, las concepciones de realidad tienen mayor peso explicativo en la formación de las creencias de neutralidad axiológica (Beta .153) que en las creencias que reconocen e incluyen los valores (Beta . 079).

\section{Conclusiones}

En este trabajo se ha intentado bosquejar una respuesta a la pregunta cómo y por qué modelizar la complejidad de los sistemas de pensamiento. El pensamiento y el conocimiento no son un reflejo pasivo de una realidad preconstituida. Por el contrario, hay un bucle recursivo a través del cual el pensamiento construye la realidad al tiempo que es constituido por ésta. Es por esta razón que emergen dos desafíos concomitantes: la problematización de la realidad y la problematización del pensamiento. Estos dos desafíos se encuentran entrelazados en el estudio de los problemas complejos a los que se enfrentan las sociedades contemporáneas. Se ha acuñado la categoría de problemas complejos para señalar:

Un problema complejo es una construcción sociocognitiva que emerge de un proceso de problematización en el que intervienen juicios de valor.

- Un problema complejo articula aspectos ético-políticos, prácticos y epistémicos.

- Los problemas complejos requieren una estrategia de investigación interdisciplinaria puesto que los 
elementos y procesos que los componen pertenecen a distintas disciplinas.

- Un problema complejo es un metasistema que incluye la articulación de un sistema observado (la experiencia problematizada) y un sistema observador (la intersección de múltiples puntos de vista sobre dicha experiencia).

La investigación empírica de un problema complejo requiere simultáneamente un enfoque reflexivo acerca de cómo pensamos la complejidad de dicho problema. En suma, la objetivación y reflexividad de la complejidad son dos dimensiones inseparables. Por lo tanto, se ha sugerido la importancia de articular los métodos de modelado y simulación de sistemas complejos con la estrategia metacognitiva del pensamiento complejo.

Se ha propuesto un modelo epistemológico del pensamiento complejo (MEPC) como una estrategia de investigación para modelizar un meta-punto de vista de un sistema de pensamiento. Con el fin de operacionalizar metodológicamente este modelo, se ha elucidado la relación teórica entre los conceptos de paradigma, marco epistémico, creencias y actitudes en la organización de un sistema de pensamiento. Se ha mostrado la pertinencia de los métodos cualitativos y cuantitativos para la producción y el análisis de evidencia empírica sobre los distintos componentes de un sistema de pensamiento, particularmente, el análisis del discurso, las técnicas psicométricas y el análisis estadístico multivariado.

A partir de este enfoque se ha conducido una investigación empírica para modelizar el sistema de creencias científicas de las ciencias de la complejidad y la simulación social. Se ha modelizado empíricamente la multidimensionalidad del sistema de creencias científicas a través de diez escalas Likert y veintidós modelos de regresión. Un sucinto resumen y una breve ilustración empírica de este trabajo fue descripta en este artículo, la documentación completa del modelo puede encontrarse aquí (cita removida para garantizar anonimato en la evaluación). Este modelo constituye un meta-punto de vista crítico y reflexivo desde el cual las ciencias de la complejidad pueden observar su propio modo de pensamiento y problematizar los paradigmas que guían sus estrategias de construcción de conocimiento.

Construir un futuro mejor es un desafío político y científico que implica transformar los problemas complejos a los cuales nos enfrentamos. Para abordar la complejidad de estos problemas tenemos que aprender a pensar cómo pensamos. Asimismo, la ciencia puede ayudarnos a problematizar nuestro modo de pensamiento, pero para ello debe ser capaz de pensarse a sí misma. Hemos ofrecidos algunas herramientas teóricas, epistemológicas, éticas y metodológicas para el desarrollo de un pensamiento complejo y una ciencia reflexiva de la complejidad.

\section{Notas}

1 Metáfora de Kaplan Abraham (1964). Agradezco al profesor Gustavo Montenegro, psicólogo organizacional de la Universidad Nacional de Córdoba por sugerirme esta metáfora.

$\underline{2}$ El pensamiento natural y la lógica discursiva (Grize, 1996 y 2012) que caracteriza al pensamiento de sentido común también es imprescindible en ciencia, incluso cuando el pensamiento científico pueda caracterizarse como un pensamiento formal basado en operaciones lógico-matemáticas (Piaget, 1978). Esto es así por varias razones: (i) “ningún pensamiento, ninguna concepción, puede prescindir del lenguaje ordinario” (Morin, 1986, p. 203); (ii) la práctica científica requiere del diálogo, la comunicación y la comprensión entre los científicos y, por lo tanto, del lenguaje natural; (iii) las teorías y conceptualizaciones científicas utilizan un lenguaje especializado derivado del lenguaje natural. El fenomenólogo Alfred Schütz decía que el conocimiento científico producido por las ciencias sociales son construcciones de segundo orden, puesto que son modelos elaborados sobre las tipificaciones de sentido común. El positivista lógico Otto Neurath acuñó el término ballunguen para destacar que el lenguaje de la ciencia es necesariamente inexacto, una combinación de términos precisos propios del quehacer científico y otros más vagos e imprecisos provenientes del lenguaje común (Gómez, 2008; Neurath, 1983). En suma, el 
pensamiento científico no es equivalente al pensamiento formal (lógico-matemático) ni puede reducirse a este. Bien por el contrario, el pensamiento científico expresa la articulación compleja del lenguaje natural y formal.

$\underline{3}$ La primera Ley dice así: "todo objeto continúa en su estado de reposo o de movimiento uniforme en línea recta a menos que sea obligado a cambiar ese estado por fuerzas que actúen sobre él”

4 Para profundizar en la antropología compleja de Edgar Morin, véase (Gómez García, 2003; Solana Ruiz, 2001).

$\underline{5}$ Las ciencias de la complejidad emplean distintos formalismos para modelizar la estructura y simular la dinámica de los sistemas complejos, entre los que cabe destacar: los autómatas celulares, las redes complejas, los modelos basados en agentes, la dinámica de sistemas, entre otros. Para una introducción véase Lewin (1995) y Reynoso (2006).

$\underline{6}$ El término noosfera fue acuñado por Teilhard de Chardin (1965) en la obra El fenómeno humano. Edgar Morin retoma este concepto para referirse a la esfera de las cosas del espíritu producidas por la mente humana en el seno de una cultura; y propone, asimismo, la constitución de la noología, una ciencia orientada al estudio de la autoorganización de los sistemas de ideas (Morin, 1991, pp. 111-115).

7 La psicología cognitiva distingue tres tipos de memoria: la memoria sensorial (MS), la memoria de corto plazo (MCP) y la memoria de largo plazo (MLP) (Best, 2002, pp. 107-119). Esta última fue dividida por Tulving (1972) en dos constructos: la memoria episódica y la memoria semántica. La memoria episódica almacena eventos, sucesos o episodios concretos de la vida de un sujeto, por lo que se trata de una memoria personal vinculada a la biografía del individuo. Por otro lado, la memoria semántica representa el "conocimiento organizado que una persona tiene sobre las palabras y otros símbolos verbales, su significado, sus referentes y sus relaciones entre ellos” (Tulving, 1972, p. 386).

$\underline{8}$ Indica la cantidad de ítems empleada para la recolección de datos.

$\underline{9}$ Indica la cantidad final de ítems retenidos luego del análisis estadístico y pruebas de confiabilidad.

$\underline{10}$ Se recomienda que la correlación media inter-ítem se sitúe entre 0.15 y 0.50. (Cupani, 2008:256).

$\underline{11} \alpha$ El coeficiente Alfa (Alfa de Cronbach) varía entre 0 y 1 . En cuanto a la valoración teórica de la magnitud del coeficiente, algunos autores sugieren valores mayores a .60. Nunnally (1970) sugiere una magnitud .70 como mínimo aceptable para las investigaciones teóricas. Un Alfa de al menos .85 es recomendado cuando las escalas van a emplearse para tomar decisiones sobre individuos, como en los test psicológicos.

12 Entre paréntesis se indica la correlación ítem-total. La correlación entre un ítem y su factor representa el grado con el cual cada ítem mide el mismo constructo que el factor. Las correlaciones con valores bajos (menos que 0.2 o 0.3) indican que el ítem no está muy bien correlacionado con el factor, por lo que expresa, en realidad, otro constructo.

$\underline{13}$ Indica la cantidad de variables independientes (X) incluidas en el modelo de regresión.

$\underline{14}$ El coeficiente de correlación múltiple $\left(\mathrm{R}_{1.23 . .}\right)$ mide la correlación entre una variable dependiente $(\mathrm{Y})$ y un conjunto de variables independientes o explicativas $\left(\mathrm{X}_{1}, \mathrm{X}_{2} \ldots \mathrm{X}_{\mathrm{n}}\right)$.

$\underline{15}$ El coeficiente de determinación múltiple $\left(\mathrm{R}^{2}{ }_{1.23 \ldots}\right.$ ) -denominado $\mathrm{R}$ cuadrado- expresa el porcentaje de la variabilidad de la variable dependiente que, de forma conjunta, está explicada por la variación de las variables independientes incluidas en el modelo de regresión múltiple. $\mathrm{R}^{2}$ indica la proporción de la variancia explicada sobre la variancia total de la variable.

$\underline{16} \mathrm{R}^{2}$ tiende a incrementar su magnitud cuando variables adicionales son incorporadas al modelo. Para mitigar este efecto se utiliza el coeficiente de determinación múltiple ajustado $\left(\mathrm{R}_{\mathrm{a}}{ }_{\mathrm{a}}\right)$. 
$\underline{17}$ El estadístico Durbin-Watson se emplea para comprobar el supuesto de homocedasticidad, esto significa que la varianza en torno a la línea de regresión es la misma para todos los valores de la variable independiente. Cuando el supuesto de homocedasticidad es violado hay heterocedasticidad. El estadístico Durbin-Watson oscila entre 0 y 4. Idealmente valores entre 1,5 y 2,5 expresan homocedasticidad.

$\underline{18}$ El coeficiente de tolerancia es un indicador de la independencia de una variable explicativa $\left(\mathrm{X}_{1}\right)$ respecto de las otras variables explicativas $\left(\mathrm{X}_{2} . . \mathrm{X}_{\mathrm{n}}\right)$ incluidas en el modelo de regresión. La tolerancia varía entre 0 y 1 . "Un valor próximo a 1.0 denota la ausencia completa de multicolinealidad: la variable $\mathrm{X}_{\mathrm{i}}$ no presenta ninguna correlación con el resto de variables predictoras" (Cea D'Ancona, 2002, p. 52) A mayor tolerancia (valor cercano a 1) mayor independencia entre $X$ y el resto de las variables independientes. Los coeficientes de tolerancia se calculan para cada variable independiente. En la columna sólo se incluye la menor tolerancia.

19 Factor de Inflación de la Variancia (FIV). El FIV es inverso a la tolerancia. A mayor FIV mayor multicolinealidad, es decir, mayor relación entre las variables independientes. "Un valor FIV de 1.0 indica la inexistencia de relación entre las variables predictoras. Valores superiores a 10,0 expresan multicolinealidad severa” (Cea D'Ancona, 2002, p. 52). Los FIV se calculan para cada variable independiente. En la columna sólo se incluye el FIV de mayor valor.

20 Los nodos del mapa conceptual representan las variables del modelo de regresión. Los vínculos entre los nodos muestran los coeficientes Beta, parcial, semiparcial y las correlaciones de orden cero. Beta es un coeficiente estandarizado (expresado en puntuaciones Z) que indica la contribución individual de cada variable independiente a la variación de la variable dependiente. Específicamente, el coeficiente Beta expresa cuántas unidades de desviación estándar se incrementa la variable dependiente cuando la variable independiente se incrementa una unidad de desviación estándar y las otras variables se mantienen constantes. La correlación parcial cuantifica el grado de asociación entre dos variables luego de controlar el efecto de una o más variables independientes. La correlación semiparcial representa la contribución de una variable independiente al modelo. Indica en qué medida R cuadrado se incrementa con la inclusión de la variable en la ecuación de regresión. La correlación de orden cero es la correlación bivariada entre una variable independiente y la dependiente.

21 Obsérvese el coeficiente Beta. La relación entre el nodo sujeto y la inclusión de valores presenta un Beta de . 547 mientras que la relación sujeto y la neutralidad axiológica tiene un Beta de .493.

\section{Referencias}

Ashby, W. R. (1962). Principles of self-organization. En Hinez Von Foerster y George W. Zopf (Eds.), Principles of Self-Organization: Transactions of the University of Illinois Symposium (pp. 255-278). New York: Pergamon Press.

Bertalanffy, L. V. (1976). Teoría general de sistemas. Fundamentos, desarrollos, aplicaciones. Buenos Aires: Fondo de Cultura Económica.

Best, J. B. (2002). Psicología cognoscitiva. México D.F.: Thomson.

Briggs, J., y Peat, D. (1989). Espejo y reflejo: del caos al orden. Barcelona: Gedisa.

Bruning, R. H., Schraw, G. J., Norby, M. N., y Ronning, R. R. (2005). Psicología cognitiva y de la institución. Madrid: Pearson.

Bunge, M. (2009). A la caza de la realidad. Barcelona: Gedisa. 
Cabeza, R. (1987). Temas de psciología cognitiva. Buenos Aires: Tekné.

Castorina, J. A. (2007). Construcción conceptual y representaciones sociales. Buenos Aires: Miño y Dávila.

Cea D'Ancona, Á. (2002). Análisis multivariable. Teoría y práctica en la investigación social. Madrid: Síntesis.

Ciurana, E. R. (2007). Introducción al pensamiento complejo de Edgar Morin. Guadalajara: Universidad de Guadalajara Centro Universitario del Norte.

Cupani, M. (2008). Análisis psicométrico con SPSS. En Silvia Tornimbeni, Edgardo Pérez y Fabián Olaz (Eds.), Introducción a la psicometría (pp. 245-267). Buenos Aires: Paidós.

Chardin, T. d. (1965). El fenómeno humano. Madrid: Taurus.

Duveen, G., \& Lloyd, B. (1990). Social representations and the development of knowledge. Nueva York: Cambridge University Press.

Edmonds, B. (1999). Syntactic Measures of Complexity. Doctor of Philosophy, Manchester Metropolitan University, Manchester.

Foerster, H. V. (1960). On Self-Organizing Systems and Their Environments. En Marshall Yovits y Scott Cameron (Eds.), Self-Organizing Systems (pp. 31-50). Londres: Pergamon Press.

Foucault, M. (1988). On problematization. The History of the Present, 4, 16-17.

Foucault, M. (1998). Las palabras y las cosas. Una arqueología de las ciencias humanas. México: Siglo XXI.

Foucault, M. (1999a). El cuidado de la verdad. En Michel Foucault (Ed.), Obras esenciales (pp. 1005-1015). Barcelona: Paidós.

Foucault, M. (1999b). Polémica, política y problematizaciones. En Michel Foucault (Ed.), Obras esenciales (pp. 991-998). Barcelona: Paidós.

Gagné, E. D. (1991). La psicología cognitiva del aprendizaje escolar. Madrid: Aprendizaje Visor.

García, R. (1997). La epistemología genética y la ciencia contemporánea. Barcelona: Gedisa.

García, R. (2000). El conocimiento en construcción. De las formulaciones de Jean Piaget a la teoría de los sistemas complejos. Barcelona: Gedisa.

García, R. (2006). Sistemas complejos. Conceptos, método y fundamentación epistemológica de la investigación interdisciplinaria. Barcelona: Gedisa.

Gell-Mann, M. (1995). What is complexity? Complexity, 1(1), 16-19.

Gómez García, P. (2003). La antropología compleja de Edgar Morin. Homo complexus. Granada, España: Universidad de Granada.

Gómez, R. (2008). Otto Neurath: Lenguaje, ciencia y valores. La incidencia de lo político. California State University: Estados Unidos. Los Ángeles.

Grize, J.-B. (1993). Logique naturelle et représentations sociales. Textes sur les Représentations Sociales, 2(3), 19.

Grize, J.-B. (1996). Logique naturelle te communications. Paris: PUF.

Grize, J.-B. (2012). Logique naturelle et représentations sociales. En Denise Jodelet (Ed.), Les représentations sociales (pp. 170-186). Paris: Puf.

Hanson, R. (1958). Patrones de descubrimiento. Observación y explicación. Madrid, España: Alianza. 
Hernandez Forte, V. (2005). Mapas conceptuales. La gestión del conocimiento en la didáctica. DF, México: Alfaomega.

Holland, J. (1995). Hidden order: How adaptation builds complexity. Cambridge: Perseus Books.

Holland, J. (1998). Emergence. From chaos to order: Reading, MA: Addison- Wesley.

Johnson-Laird, P. N. (1983). Mental Models: Towards a Cognitive Science of Language, Inference, and Consciousness. Cambridge: Harvard University Press.

Johnson-Laird, P. N. (1987). Modelos mentales en ciencia cognitiva. En Donald Norman A. (Ed.), Perspectivas de las ciencias cognitivas (pp. 179-231). Barcelona: Paidós.

Johnson, S. (2001). Sistemas emergentes. O qué tienen en común hormigas, neuronas, ciudades y software. Madrid: Fondo de Cultura Económica.

Koyré, A. (1999). Del mundo cerrado al universo infinito. Madrid: Siglo XXI.

Latour, B. (1999). La Esperanza de Pandora. Ensayos sobre la Realidad de los Estudios de la Ciencia. Barcelona: Gedisa.

Le Moigne, J.-L. (1990). La Modélisation des systèmes complexes. Paris: Dunod.

Lewin, R. (1995). Complejidad. El caos como generador de orden. Barcelona, España: Tusquets.

Likert, R. (1932). A Technique for the Measurement of Attitudes. Archives of Psychology, 140, 44-53.

Maldonado, C. E. (1999). Esbozo de una filosofía de la lógica de la complejidad. En Carlos Maldonado (Ed.), Visiones sobre la Complejidad (pp. 9-27). Bogotá: Ediciones El Bosque.

Maldonado, C. E. (2007). Complejidad: ciencia, pensamiento y aplicación. Buenos Aires: Universidad Externado de Colombia.

Maruyama, M. (1980). Mindscapes and Science Theories. Current Anthropology, 21(5), 589-608.

Maturana, H., y Varela, F. (1972). Autopoietic system. Santiago de Chile: Facultad de Ciencias.

Maturana, H., y Varela, F. (2003). De máquinas y seres vivos: autopoiesis, la organización de lo vivo. Buenos Aires: Lumen.

Miller, J. H., y Page, S. E. (2007). Complex Adaptive Systems: An Introduction to Computational Models of Social Life. Princeton: Princeton Studies in Complexity.

Minsky, M. (1965). Matter, Mind and Models. Paper presented at the International Federation of Information Processing Congress, Vol 1, pp. 45-49.

Morales Vallejo, P., Urosa Sanz, B., y Blanco Blanco, A. (2003). Construcción de Escalas de Actitudes Tipo Likert. Cuadernos de Estadísticas $N^{\circ} 26$. Madrid: La Muralla.

Morin, E. (1973). El paradigma perdido. Ensayo de bioantropología. Barcelona: Kairós.

Morin, E. (1977). El Método I. La naturaleza de la naturaleza. Madrid: Cátedra.

Morin, E. (1984). Ciencia con Conciencia. Barcelona: Anthropos. Editorial del Hombre.

Morin, E. (1986). El Método III. El conocimiento del conocimiento. Madrid: Cátedra.

Morin, E. (1990). Introducción al Pensamiento Complejo. Barcelona: Gedisa.

Morin, E. (1991). El Método IV. Las ideas. Madrid: Cátedra. 
Morin, E. (1998). El Método IV. Las ideas. Madrid: Cátedra.

Morin, E. (1999). La cabeza bien puesta. Repensar la reforma. Reformar el pensamiento. Buenos Aires: Nueva Visión.

Morin, E. (2001). El Método V. La humanidad de la humanidad. La identidad humana. Madrid: Cátedra.

Morin, E. (2007). Complexité restreinte et complexité générale. En Edgar Morin y Jean-Louis Le Moigne (Eds.), Intelligence de la complexité: épistémologie et pragmatique, Colloque de Cerisy, 2005 (pp. 28-50). La Tour d’Aigues: Éditions de l’Aube.

Moscovici, S. (1979). El psicoanálisis, su imágen y su público. Buenos Aires: Huemul.

Neurath, O. (1983). Pseudorationalism of falsification. En Otto Neurath (Ed.), Philosophical Papers 1913-1946 (pp. 121-131). Boston, United States of America: Reidel.

Nicolescu, B., Bianchi, F., Morin, E., y Motta, R. D. (1994). Carta a la transdisciplinariedad Consulta: 10/9, 2008, Recuperado de http://www.pensamientocomplejo.com.ar/docs/files/aavv carta a la interdisciplinariedad.pdf

Nunnally, J. C. (1970). Introducción a la medición psciológica. Buenos Aires: Paidós.

Piaget, J. (1973). Psicología y epistemología. Barcelona: Ariel.

Piaget, J. (1978). Introducción a la epistemología genética. 1. El pensamiento matemático. Buenos Aires, Argentina: Paidós.

Piaget, J. (1979). Tratado de lógica y conocimiento científico. I. Naturaleza y métodos de la epistemología. Buenos Aires: Paidós.

Piaget, J., y García, R. (2008). Psicogénesis e historia de la ciencia. México DF: Siglo XXI.

Prigogine, I. (1999). Las leyes del caos. Barcelona: Crítica.

Prigogine, I., y Nicolis, G. (1997). La estructura de lo complejo. Madrid: Alianza.

Prigogine, I., y Stengers, I. (1983). La nueva alianza. Metamorfosis de la ciencia. Madrid: Alianza.

Putnam, H. (1994). Las mil caras del realismo. Barcelona: Paidós.

Putnam, H. (2004). El desplome de la dicotomía hecho-valor y otros ensayos. Barcelona: Paidós.

Quillian, M. R. (1968). Semantic memory. En Marvin Lee Minksy (Ed.), Semantic information processing (pp. 227-270). Cambridge, MA: MIT Press.

Reynoso, C. (2006). Complejidad y caos. Una exploración antropológica. Buenos Aires: Editorial SB.

Reynoso, C. (2009). Modelos o metáforas. Crítica del paradigma de la complejidad de Edgar Morin. Buenos Aires: Editorial SB.

Ricoeur, P. (1996). Si mismo como otro. México: Siglo XXI.

Rodríguez, R. J. (2010). Herramientas informáticas para la representación del conocimiento. Subjetividad y Procesos Cognitivos, 14(2), 217-232.

Rodríguez Zoya, L. (2013). El modelo epistemológico del pensamiento complejo. Análisis crítico de la construcción de conocimiento en sistemas complejos. Tesis de Doctorado en Sociología y Ciencias Sociales, Universidad de Buenos Aires y Universidad de Toulouse, Toulouse.

Roggero, P. (2008). Pour une sociologie d’après La Méthode. Communications, 82, 143-159. 
Simon, H. (1973). La arquitectura de la complejidad. En Herbert Simon (Ed.), Las ciencias de lo artificial (pp. 125-169). Barcelona: A.T.E.

Solana Ruiz, J. L. (2001). Antropología y complejidad humana. La antropología compleja de Edgar Morin. . Granada: Editorial Comares-Universidad de Jaen.

Tulving, E. (1972). Episodic and Semantic Memory. En Endel Tulving y Wayne Donaldson (Eds.), Organization of Memory (pp. 381-402). New York: Academic Press.

van Dijk, T. A. (1999). Ideología. Una aproximación multidisciplinaria. Sevilla: Gedisa.

Varsavsky, O. (1975). Marco Histórico Constructivo para estilos sociales, proyectos nacionales y sus estrategias. Buenos Aires: Centro Editor de América Latina.

Varsavsky, O. (1982). Ideas básicas para una filosofía constructiva. En Oscar Varsavsky (Ed.), Obras Escogidas (pp. 365-413). Buenos Aires: Centro Editor de América Latina.

Vilar, S. (1997). La nueva racionalidad. Comprender la complejidad con métodos transdisciplinarios. Barcelona, España: Kairós.

Voloshinov, V. (1976). El signo ideológico y la filosofía del lenguaje. Buenos Aires: Nueva Visión.

Vygotski, L. (1995). Pensamiento y Lenguaje. Barcelona: Paidós.

Waldrop, M. M. (1992). Complexity: The Emerging Science at the Edge of Order and Chaos. New York: Touchstone.

Wallerstein, I. (1996). Abrir las ciencias sociales. Informe de la Comisión Gulbenkian para la reestructuración de las ciencias sociales. México: Siglo XXI.

Weaver, W. (1948). Science and complexity. American Scientist, 36, 536-544.

Whitehead, A. N. (1944). Modos de pensamiento. Buenos Aires: Losada.

Woolgar, S. (1991). Ciencia: abriendo la caja negra. Barcelona, España: Anthropos. 